The Effects of Pressure Sensor Acoustics on Airdata Derived From a High-Angle-of-Attack Flush Airdata Sensing (HI-FADS) System

Stephen A. Whitmore and Timothy R. Moes

NASA Ames Research Center, Dryden Flight Research Facility, Edwards, California

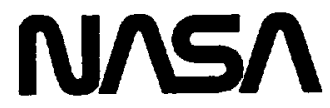

National Aeronautics and

Space Administration

Ames Research Center

Dryden Flight Research Facility

Edwards, California 93523-0273 



\title{
THE EFFECTS OF PRESSURE SENSOR ACOUSTICS ON AIRDATA DERIVED FROM A HIGH-ANGLE-OF-ATTACK FLUSH AIRDATA SENSING (HI-FADS) SYSTEM
}

\author{
Stephen A. Whitmore, Ph.D.* and Timothy R. Moes* \\ NASA Ames Research Center \\ Dryden Flight Research Facility \\ Edwards, California
}

\begin{abstract}
The accuracy of a nonintrusive high-angle-of-attack flush airdata sensing (HI-FADS) system was verified for quasi-steady fight conditions up to $55^{\circ}$ angle of attack during the F-18 High Alpha Research Vehicle (HARV) Program. The system is a matrix of nine pressure ports arranged in annular rings on the aircraft nose. The complete airdata set is estimated using nonlinear regression. Satisfactory frequency response was verified to the system Nyquist frequency $(12.5 \mathrm{~Hz})$. The effects of acoustical distortions within the individual pressure sensors of the nonintrusive pressure matrix on overall system performance are addressed. To quantify these effects, a frequencyresponse model describing the dynamics of acoustical distortion is developed and simple design criteria are derived. The model adjusts measured HI-FADS pressure data for the acoustical distortion and quantifies the effects of internal sensor geometries on system performance. Analysis results indicate that sensor frequency response characteristics vary greatly with altitude, thus it's difficult to select satisfactory sensor geometry for all altitudes. The solution uses presample filtering to eliminate resonance effects, and short pneumatic tubing sections to reduce lag effects. Without presample signal conditioning the system designer must use the pneumatic transmission line to attenuate the resonances and accept the resulting altitude variability.
\end{abstract}

*Aerospace Engineer. Member AIAA.

Copyright (C) 1990 by the American Institute of Aeronautics and Astronautics, Inc. No copyright is asserted in the United States under Title 17, U.S. Code. The U.S. Government has a royalty-free license to exercise all rights under the copyright claimed herein for Governmental purposes. All other rights are reserved by the copyright owner.

\section{Nomenclature}

$A_{c}$

$A(s)$

$B(s)$

BVP

$C_{p}$

$c$

$D$

ESP

ESP101

e

$\mathcal{F}$

$F(\ldots)$

FADS

FFT

FRP

$f$

HARV

HI-FADS

Hp

$i$

j

$L$

$\mathcal{L}$

$M_{L}$

Mo cross-sectional area of pneumatic tubing intermediate coefficient of integration intermediate coefficient of integration boundary value problem pressure coefficient sonic velocity pressure tubing diameter, in. electronically scanned pressure $0^{0}$ clock angle, $0^{0}$ cone angle, HI-FADS pressure complex exponential Fourier transform operator nonlinear functional (potential flow) flush airdata sensing fast Fourier transform fiberglass reinforced plastic input frequency high alpha research vehicle high-angle-of-attack flush airdata system sensing

pressure altitude HI-FADS pressure port index complex constant, $(-1)^{1 / 2}$ length of pneumatic tubing, $\mathrm{ft}$ Laplace transform Mach number from output pressures Mach number from input pressures 


\begin{tabular}{|c|c|}
\hline$m$ & summation index \\
\hline$N$ & number of HI-FADS pressure ports \\
\hline$P$ & ambient pressure \\
\hline$P_{L}(f)$ & Fourier domain \\
\hline$P_{L}(s)$ & $\begin{array}{l}\text { pressure function output (frequency } \\
\text { domain) }\end{array}$ \\
\hline$P_{0}(f)$ & Fourier domain \\
\hline$P_{0}(s)$ & $\begin{array}{l}\text { pressure function input (frequency } \\
\text { domain) }\end{array}$ \\
\hline$\left(\frac{P_{t}(s)}{P_{0}(s)}\right)_{1 h}$ & second order transfer function \\
\hline$P(x, s)$ & $\begin{array}{l}\text { general pressure function (frequency } \\
\text { domain) }\end{array}$ \\
\hline $\mathrm{PCM}$ & pulse code modulation \\
\hline PSD & power spectral density \\
\hline$p_{\infty}$ & aircraft static pressure \\
\hline$p_{j}$ & pressure at $j$ th HI-FADS orifice \\
\hline$p_{L}(t)$ & pressure function output (time domain) \\
\hline$p_{0}(t)$ & pressure function input (time domain) \\
\hline$p(x, t)$ & $\begin{array}{l}\text { general pressure function (time } \\
\text { domain) }\end{array}$ \\
\hline$p\left(\phi_{i}, \lambda_{i}\right)$ & $\begin{array}{l}\text { pressure value at FADS coordinates, } \\
\qquad \phi_{i}, \lambda_{i}\end{array}$ \\
\hline $\bar{Q}$ & incompressible dynamic pressure \\
\hline$q c$ & compressible dynamic pressure \\
\hline$R$ & acoustic resistance of pneumatic tubing \\
\hline$s$ & Laplace operator \\
\hline$T(x, t)$ & temperature function \\
\hline$t$ & time coordinate \\
\hline$U(x, t)$ & velocity function \\
\hline$V$ & enclosed transducer volume, in ${ }^{3}$ \\
\hline $\mathcal{v}$ & frequency domain transfer function \\
\hline$v$ & time domain describing function \\
\hline$x$ & spatial coordinate \\
\hline$\alpha$ & angle of attack (def. 1) \\
\hline$\alpha$ & $\begin{array}{l}\text { complex plane frequency variable } \\
\text { (def. 2) }\end{array}$ \\
\hline$\alpha_{L}$ & angle of atttack from output pressures \\
\hline$\alpha_{0}$ & angle of atttack from input pressures \\
\hline$\beta$ & angle of sideslip \\
\hline$\delta$ & coefficient of higher order harmonics \\
\hline
\end{tabular}

$\begin{array}{ll}\varepsilon & \text { HI-FADS calibration parameter } \\ \zeta & \text { damping ratio } \\ \lambda & \text { HI-FADS cone angle coordinate } \\ \mu & \text { dynamic viscosity } \\ \rho_{0} & \text { inital or ambient density } \\ \tau & \text { dummy variable of integration } \\ & \text { (def. 1) } \\ \tau & \text { acoustical time lag (def. } 2 \text { ) } \\ \phi & \text { HI-FADS clock angle coordinate } \\ \omega_{n} & \text { natural frequency } \\ & \text { Introduction }\end{array}$

Contemporary design requirements for some highangle-of-attack and most hypersonic or low observable aircraft do not allow for airdata measurement using conventional noseboom instrumentation. Instead, requirements for these classes of vehicles mandate that airdata be measured nonintrusively, that is, without placing a sensing probe directly into the flow stream. One very promising class of nonoptical, nonintrusive airdata systems, the flush airdata sensing (FADS) system ${ }^{1-3}$ uses a matrix of surface pressure measurements to infer free-stream airdata indirectly.

A particular system designed for high-angle-ofattack measurements, the high-angle-of-attack flush airdata sensing (HI-FADS) system, Fig. 1, was verified to be accurate for quasi-steady conditions up to $55^{\circ}$ angle of attack during phase one of the F-18 high alpha research vehicle (HARV) flight test program. Preliminary test results were reported in Ref. 1. The HI-FADS system consists of a matrix of pressure ports arranged in annular rings on the aircraft nose, and estimates the complete airdata set using potential flow modeling and nonlinear regression.

The system performed well for steady or moderate maneuvering fiight conditions and computations were performed at a rate of $25 \mathrm{samples} / \mathrm{sec}$. Satisfactory frequency response was verified up to the system Nyquist frequency of $12.5 \mathrm{~Hz}{ }^{1}$ For rapid maneuvering and unsteady flight regimes, where higher frequency airdata could be utilized, there is some question as to how well the HI-FADS system would perform. There are two primary reasons for this uncertainty: (1) unmodeled, unsteady aerodynamic effects, and (2) acoustical distortion within the individual pressure sensors of the HI-FADS surface pressure matrix. Research pre- 
sented in Ref. 4 addresses the unmodeled, unsteady aerodynamics. This paper will address the effects of acoustical distortion.

Background information on the physics of pressure sensor acoustical distortion is presented first. Next, an accurate model which describes the dynamics of acoustical distortion will be presented. The model, which has been verified extensively ${ }^{5-8}$ will be briefly verified for the HI-FADS configuration by comparison to laboratory test results. Then system design criteria will be developed from the model. Application of these criteria to the HI-FADS system design will be discussed. Using the techniques of spectral deconvolution ${ }^{7-9}$ the model is used to adjust measured HI-FADS pressure data for the effects of acoustical distortion and the results are merged with other high-frequency surface pressure flight data to synthesize a representative surface pressure data set. Using the synthesized surface pressure data set for sensor inputs, the effects of various internal sensor geometries will be analyzed and qualitative comparisons will be presented. Various system design difficulties will be discussed.

\section{Airdata Measurement System}

The HI-FADS configuration has a simple hardware arrangement with the basic fixture being a fiberglassreinforced-plastic (FRP) cap, mounted on the nose of the F-18 HARV. A set of 250.06 -in. inside diameter pressure orifices, arranged in 4 annular rings, were drilled in the nosecap. Flight tests conducted during phase one of the HARV Program, indicated that airdata could be measured satisfactorily using a subset of nine pressure ports from two of the rings. All results presented in this paper will use the 9-port configuration. Pressures at the nosecap were sensed by a multiple transducer, electronically scanned pressure (ESP) module remotely mounted on a structural bulkhead in the aircraft nose cavity. The ESP module, which consists of differential transducers, was referenced to a single, high-accuracy absolute pressure transducer mounted in the aircraft nose cavity. High-frequency dynamics in the reference pressure were damped by a $50.0 \mathrm{in}^{3}$ reference tank also mounted in the aircraft nose. The temperature environments of both the ESP module and the reference transducer were controlled by wrapping the units in heater blankets to maintain an operating temperature of approximately $110^{\circ} \mathrm{F}$. For the ESP module the estimated accuracy is $\pm 1.0 \mathrm{lb} / \mathrm{ft}^{2}$ and for the reference transducer, the estimated accuracy is $\pm 0.50 \mathrm{lb} / \mathrm{ft}^{2}$ (Ref. 1). The outputs from both the ESP module and the reference transducer were digitized by pulse code modulation (PCM) and telemetered to the ground at 25 samples/sec. Because of telemetry limitations, higher sample rates were not practical for the HARV flight tests.

Since the ESP module was electronically scanned (multiplexed), any information with significant power which lies beyond the Nyquist frequency of the scan $(12.5 \mathrm{~Hz})$ will be aliased to a lower frequency and will distort the measured pressure values. Since the transducer output is multiplexed-the equivalent of time sampling-posttransduction signal conditioning cannot be used without eliminating information in the band of interest. For the HARV HI-FADS installation, the sensing ESP pressure transducer was located remotely from the surface, and 8-ft lengths of 0.06 -in.diameter flexible pneumatic tubing were used to transport pressure from the surface to the transducer. Each ESP transducer has an internal volume of less than $0.01 \mathrm{in}^{3}$. As discussed in Ref. 1, the previously mentioned tubing geometries were selected to give the sensors low-pass characterisitcs and thus serve as crude antialiasing filters.

For the remainder of the paper, the term "transducer" will be used to describe the actual ESP physical transduction device. The term "sensor" will be used to describe the transducer and all associated pneumatic tubing, pressure fittings, and so on. The term "system" will be used to describe the collection of all nine HIFADS measurement sensors, the pressure reference system, and the associated data acquisition, telemetry, and storage hardware. A schematic of the $\mathrm{HI}-$ FADS hardware arrangement is presented in Fig. 1. A schematic of the intemal geometry of the HI-FADS pressure sensing system is presented in Fig. 2. More detail conceming the HI-FADS system hardware and the HARV research data acquisition system may be found in Ref. 1.

The measured pressure data, $p\left(\phi_{i}, \lambda_{i}\right)$, were related to the free-stream airdata quantities using a modified potential flow model ${ }^{1}$

$$
p\left(\phi_{i}, \lambda_{i}\right)=F\left(\alpha, \beta, q_{c}, p_{\infty}, \phi_{i}, \lambda_{i}, \varepsilon\right), i=1, N
$$

and all nine pressure observations were used simultaneously to estimate the four airdata parameters: compressible dynamic pressure $\left(q_{c}\right)$, angle of attack $(\alpha)$, 
angle of sideslip $(\beta)$, and static pressure $\left(p_{\infty}\right)$, using a least-squares criterion and nonlinear regression. Here $\phi_{i}$ and $\lambda_{i}$ are the clock and cone angles of the $i$ th HI-FADS pressure port, $\varepsilon$ is a calibration parameter, and $N$ is the number of ports (nine in this case). Using these four basic airdata parameters, most airdata quantities of interest may be calculated directly. The use of an overdetermined (more observations than states) analysis minimizes the effects of errors in any single pressure measurement. The resulting algorithm, hereafter referred to as the "HI-FADS algorithm," is robust and accurate. Excellent steady-state system performance has been verified over the entire subsonic Mach number range and up to $55^{\circ}$ angle of attack. Specific details concerning the algorithm implementation may be found in Ref. 1.

\section{Sensor Acoustical Model}

Referring to Fig. 2, the sensor configuration is modeled as a straight cylindrical tube with an axisymmetric volume, which models the intemal volume of the pressure transducer attached to its downstream end. The tube is considered to be of constant diameter $(D)$ and length $(L)$ with a longitudinal coordinate $(x)$ defined from the upstream-end of the tube. Pressure, density, temperature, and flow velocity within the tube are modeled as one-dimensional functions of longitudinal position and time, and are represented by the symbols, $p(x, t), T(x, t)$, and $U(x, t)$. For this analysis the flow velocity, $U(x, t)$, although actually a function of radial position within the tube, is approximated by its radial average. The input pressure, the value at $x=$ 0 , is represented by the symbol $p_{0}(t)$. The measured pressure at the transducer, the value at $x=L$, is represented by the symbol $p_{L}(t)$.

Pressure variations at the surface propagate as longitudinal waves through the connective tubing to the transducer. The wave propagation is damped by frictional attenuation along the walls of the tubing. When the wave reaches the downstream-end of the tubing, it reflects back up the tube and may either damp or amplify incoming pressure waves. The frictional damping and wave interference produce a magnitude distortion and phase delay in the measured pressure signal. The magnitude of the distortion and phase delay are dependent on the internal geometry, surface crossflow on the sensor pressure port, and the free-stream flight conditions-primarily altitude. The speed of the longitudinal wave is somewhat slower than the local sonic velocity but considerably faster than the internal flow velocity. Analytical and experimental results ${ }^{5-9}$ indicate that for modem, low-volume installations, internal flow velocities are considered to be small.

The dynamics of the acoustical wave propagation are described accurately by a boundary value problem (BVP) derived from the Navier-Stokes equations of momentum and continuity. ${ }^{5,9}$ The acoustical wave propagates according to

$$
\frac{\partial^{2} p(x, t)}{\partial t^{2}}+\frac{R}{\rho_{0}} \frac{\partial p(x, t)}{\partial t}=c^{2} \frac{\partial^{2} p(x, t)}{\partial x^{2}}
$$

Subject to the boundary conditions

$$
\begin{aligned}
\frac{d^{2} p(L, t)}{d t^{2}}+ & \frac{R}{\rho_{0}} \frac{d p(L, t)}{d t} \\
& +\frac{A_{c} c^{2}}{V}\left\{\frac{\partial p(x, t)}{\partial x}\right\}_{x=L}=0 \\
& p(0, t)=p_{0}(t)
\end{aligned}
$$

and the initial condition

$$
p(x, 0)=P_{a}
$$

In equations (1a) and (1b), $R$ is the acoustical resistance of the system and as developed in Ref. 7 for laminar flow

$$
R=\frac{32 \mu}{D^{2}}
$$

and $A_{c}$ is the cross-sectional area of the tube. By evaluating the acoustical resistance based on Blasius friction law ${ }^{10}$ the BVP may be easily extended to describe turbulent flow. This extension is derived in detail in Refs. 5 and 8 . In general, for the case of arbitrary pressure inputs the BVP cannot be solved analytically. However, numerical techniques for solving the BVP for arbitrary inputs are developed in Refs. 5 and 8. The BVP can be solved in closed form, however, for the case of sinusoidal inputs-commonly referred to as the "frequency response" of the model.

\section{Frequency Response of the Acoustical Model}

The frequency response solution is developed by first taking the Laplace transform of equations ( $1 a$ ) and 
(1c) and removing the constant initial conditions by subtracting the intial pressure value. The result is

$$
\begin{gathered}
\left(s^{2}+\frac{R}{\rho_{0}} s\right) P(x, s)=c^{2} \frac{\partial^{2} P(x, s)}{\partial x^{2}} \\
\left(s^{2}+\frac{R}{\rho_{0}} s\right) P_{L}(s)+\frac{A_{c} c^{2}}{V}\left\{\frac{\partial P(x, s)}{\partial x}\right\}_{x=L}=0 \\
P_{0}(s)=\mathcal{L}\left[p_{0}(t)\right]
\end{gathered}
$$

Integrating with respect to $x$ gives

$$
P(x, s)=A(s) \mathrm{e}^{\sqrt{\alpha} x / c}+B(s) \mathrm{e}^{-\sqrt{\alpha} x / c}
$$

and differentiating equation (3a),

$$
\frac{\partial P(x, s)}{\partial x}=\frac{\sqrt{\alpha}}{c}\left[A(s) \mathrm{e}^{\sqrt{\alpha} x / c}-B(s) \mathrm{e}^{-\sqrt{\alpha} x / c}\right]
$$

where,

$$
\alpha=s^{2}+\frac{R}{\rho_{0}} s
$$

Evaluating $P(x, s)$ (eq. (3a)) at $x=0$, and $\frac{\partial P(x, s)}{\partial x}$ (eq. (3b)) at $x=L$ and solving for $A(s)$, and $B(s)$, then

$$
A(s)=\frac{\frac{1}{2} P_{0}(s)\left[1-\frac{V \sqrt{\alpha}}{A_{c} c}\right] e^{-\sqrt{\alpha} L / c}}{\cosh [\sqrt{\alpha} L / c]+\frac{V \sqrt{\alpha}}{A_{c} c} \sinh [\sqrt{\alpha} L / c]}
$$

and

$$
\begin{aligned}
B(s)= & P_{0}(s) \\
& -\frac{\frac{1}{2} P_{0}(s)\left[1-\frac{V \sqrt{\alpha}}{A_{c} c}\right] \mathrm{e}^{-\sqrt{\alpha} L / c}}{\cosh [\sqrt{\alpha} L / c]+\frac{V \sqrt{\alpha}}{A_{c} c} \sinh [\sqrt{\alpha} L / c]}
\end{aligned}
$$

Letring $s=2 \pi j f$ for the Fourier transform and evaluating at $x=L$, simplifying and reducing gives,

$$
\frac{P_{L}(f)}{P_{0}(f)}=\frac{1}{\cosh [\sqrt{\alpha} L / c]+\frac{V \sqrt{\alpha}}{A_{c} c} \sinh [\sqrt{\alpha} L / c]}
$$

where,

$$
\alpha=-\left(4 \pi^{2} f^{2}\right)+j\left(2 \pi \frac{R}{\rho_{0}} f\right)
$$

Equation (4) is a simple frequency response model in which the ratio of the complex spectra is given explicitly as a function of the sensor geometry, the initial flow density (usually taken as ambient), and the frequency of the input sinusoid. Results similar to equations (3e) and (4) are derived in Refs. 11 and 12.

\section{Verification of the Acoustical Model}

The acoustical model of equations (1a)-(1d), has been extensively verified by comparisons of numerical solutions to both laboratory and flight data. The results of this verification are presented in detail in Refs. 5-8. The closed form solution, equation (4), has been verified by extensive comparisons to both numerical solutions and laboratory data. Figure 3 presents a sample frequency response comparison. Depicted in Fig. 3 are frequency response comparisons of laboratory data and values generated using equation (4). In this figure, data were obtained using the HI-FADS pressure sensor geometry ( $L=8 \mathrm{ft}, D=0.06$ in., and $V=0.01 \mathrm{in}^{3}$ ) and an ESP transducer. The data presented were obtained at $2300-\mathrm{ft}$ altitude. Although the lab data indicate that the acoustical model is slightly less damped than the actual sensor, considering that the analyses of equations (1a)-(1d) do not consider tubing roughness or constrictions, the comparisons are quite favorable. Detailed descriptions of the laboratory and flight experimental setups may be found in Refs. 5-8.

Substituting these expressions into equation (3a),

$$
\begin{aligned}
P(x, s) & =\left\{\frac{\frac{1}{2} P_{0}(s)\left[1-\frac{V \sqrt{\alpha}}{A_{c} c}\right] \mathrm{e}^{-\sqrt{\alpha} L / c}}{\cosh [\sqrt{\alpha} L / c]+\frac{V \sqrt{\alpha}}{A_{c} c} \sinh [\sqrt{\alpha} L / c]}\right\} \mathrm{e}^{\sqrt{\alpha} x / c} \\
& +\left\{P_{0}(s)-\frac{\frac{1}{2} P_{0}(s)\left[1-\frac{V \sqrt{\alpha}}{A_{0} c}\right] \mathrm{e}^{-\sqrt{\alpha} L / c}}{\cosh [\sqrt{\alpha} L / c]+\frac{V \sqrt{\alpha}}{A_{c} c} \sinh [\sqrt{\alpha} L / c]}\right\} \mathrm{e}^{-\sqrt{\alpha} x / c}
\end{aligned}
$$




\section{Convolution and Deconvolution of Pressure Signals}

Equation (4), describes the behavior of the pressure sensor as a function of the frequency of the input sinusoid. It has multiple resonances, and can be applied to arbitrary input data by decomposing the input signal into its Fourier components by way of Fourier Transform techniques ${ }^{13,14}$. Mathematically, the physical process may be modeled by the convolution

$$
p_{L}(t)=\int_{0}^{t} v(t-\tau) p_{0}(\tau) d \tau
$$

where, $v(t)$, is a describing function for the sensor dynamics. Evaluating the Fourier transform of equation (5a), then

$$
\mathcal{F}\left[p_{L}(t)\right]=\mathcal{F}\left[\int_{0}^{t} v(t-\tau) p_{0}(\tau) d \tau\right]=\mathcal{V}(f) P_{0}(f)
$$

where,

$$
\begin{aligned}
\mathcal{V}(f) & =\frac{P_{L}(f)}{P_{0}(f)} \\
& =\frac{1}{\cosh [\sqrt{\alpha} L / c]+\frac{V \sqrt{\alpha}}{A_{e} c} \sinh [\sqrt{\alpha} L / c]}(5 \mathrm{c})
\end{aligned}
$$

and is referred to as the sensor "transfer function." The time domain equivalent of the output spectrum, $P_{L}(f)$, may be generated by numerically evaluating the inverse Fourier transform.

The numerical transform operations are easily mechanized using fast Fourier transform (FFT) techniques. The specific analysis procedure, referred to as "spectral convolution," is depicted schematically in Fig. 4. Since finite record lengths are being used, to prevent spectral power leakage ${ }^{13-15}$ care must be taken to appropriately window the input time history data. For this analysis a cosine-taper window was used. This procedure is shown in block 1 of Fig. 4 . The data are then transformed using the FFT procedure (block 2). To eliminate noise introduced by the discrete transformation, as well as noise in the original data, the resulting spectra are smoothed using frequency averaging. For this analysis, a two- pass recursive implementation ${ }^{14}$ was used.To eliminate frequency-shift distortions, the first pass was performed forward in frequency and the second pass was performed backward in frequency (block 3). The resulting smoothed spectrum is convolved to account for acoustical distortion by multiplying by the transfer function of equation (5c). This procedure is shown in block 4. Finally the results are inverse transformed to give the time history (block 5).

The procedure is easily reversible, and up to the Nyquist frequency of the system, it allows the input to be inferred from a measured output. The reverse process is performed identically, except that the inputs and outputs are reversed and in block 4 the smoothed spectrum is divided (instead of multiplied) by the transfer function of equation (5c). This process is referred to as "spectral deconvolution," and is depicted schematically in Fig. 5.

\section{Formulation of Qualitative Design Criteria}

If the denominator terms of equation (4) are expanded in a Taylor's series ${ }^{16}$

$$
\cosh \left[\frac{\sqrt{\alpha} L}{c}\right]=\sum_{m=0}^{\infty}\left\{\frac{\left[\frac{L}{c}\right]^{2 m} \alpha^{m}}{(2 m) !}\right\}
$$

and

$$
\sinh \left[\frac{\sqrt{\alpha} L}{c}\right]=\sum_{m=0}^{\infty}\left\{\frac{\left[\frac{L}{c}\right]^{2 m+1} \alpha^{(2 m+1) / 2}}{(2 m+1) !}\right\}
$$

and terms in like powers of $\alpha$ are collected, then equation (4) may be expressed as an infinite series of harmonics

$$
\frac{P_{L}(s)}{P_{0}(s)}=\frac{1}{1+\sum_{m=0}^{\infty}\left\{\left[\frac{\left(\frac{l}{c}\right)^{2 m}}{(2 m) !}\right]+\frac{V}{A_{c} c}\left[\frac{\left(\frac{l}{c}\right)^{2 m-1}}{(2 m-1) !}\right]\right\} \alpha^{m}}
$$

evaluating

$$
\alpha=s^{2}+\frac{R}{\rho_{0}} s
$$


and regrouping terms then

of the full-wave model. Thus, if the resonance resulting from the dominant harmonic is eliminated by ad-

$$
\frac{P_{L}(s)}{P_{0}(s)}=\frac{1}{1+\left(\frac{L^{2}}{2 c^{2}}+\frac{L V}{A_{c} c^{2}}\right)\left(s^{2}+\frac{R}{\rho_{0}} s\right)+\left(\frac{L^{4}}{24_{c}^{4}}+\frac{L^{3} V}{6 A_{c} L^{2}}\right)\left(s^{2}+\frac{R}{\rho_{0}} s\right)^{2}+\ldots}
$$

If all terms (in $s$ ) of equation (6d) of an order greater than 2 are neglected, then a reduced-order model which describes the behavior the primary or dominant harmonic results,

$$
\left(\frac{P_{L}(s)}{P_{0}(s)}\right)_{1 h}=\frac{1}{\left(\frac{L V}{A_{c} c^{2}}\right)\left\{\left[\frac{L A_{c}}{2 V}\right]\left[1+\frac{(L R)^{2}}{12\left(\rho_{0} c\right)^{2}}\right]+\left[1+\frac{(L R)^{2}}{6\left(\rho_{0} c\right)^{2}}\right]\right\} s^{2}+\left[\frac{L^{2}}{2 c^{2}} \frac{L V}{A_{c} c^{2}}\right] \frac{R}{\rho_{0}} s+1}
$$

$$
\left(\frac{P_{L}(s)}{P_{0}(s)}\right)_{1 h}=\frac{1}{\frac{1}{\omega_{n}^{2}} s^{2}+2 \frac{\zeta}{\omega_{s}} s+1}
$$

with a natural frequency given by (assuming laminar flow)

$$
\omega_{n}^{2}=\frac{\left(\frac{A_{f} c^{2}}{L V}\right)}{\left\{\left[\frac{L A_{f}}{2 V}\right]\left[1+\frac{(L R)^{2}}{12\left(\rho_{0} c\right)^{2}}\right]+\left[1+\frac{(L R)^{2}}{6\left(\rho_{0} c\right)^{2}}\right]\right\}}
$$

a damping ratio given by

$$
\zeta+\frac{R \omega_{n}}{2 \rho_{0}}\left[\frac{L^{2}}{2 c^{2}}+\frac{L V}{A_{c} c^{2}}\right]
$$

and a steady-state time constant given by

$$
\tau=\frac{2 \zeta}{\omega_{n}}=\frac{128 \mu L\left[V+\frac{L A_{c}}{2}\right]}{\pi D^{4} c^{2} \rho_{0}}
$$

The time constant of equation (6i), is identical to the value predicted by the first-order analysis of Ref. 17-long considered to be the best available prediction of acoustically-induced pressure measurement lag. Taken together, equations $(6 \mathrm{~g})$ through (6i) constitute an important set of qualitative design criteria.

Extensive lab tests ${ }^{6}$ and numerical evaluation equation (4) (full-wave model) indicate that peak magnitudes of the higher order harmonics are smaller than the peak magnitude of the dominant harmonic. Furthermore, evaluation of equation $(6 \mathrm{~g})$ (reduced-order model) for many geometries indicates that the natural frequency and peak magnitude of the second-order model are a good approximation of the first harmonic
Equation (6e) is a second-order filter of the form herence to the design rules, either by geometrical design or presample low-pass filtering, then the sensor will not resonate.
Equation (6h) indicates that the sensor damping ratio is inversely proportional to flow density. Since density varies inversely with altitude, a sensor which is underdamped at low altitude may be highly overdamped at high altitudes. Again, use of the design criteria to describe the first harmonic allows for the geometry of the pressure sensor to be quickly tailored to a particular frequency band or operating altitude.

Similar numerical evaluations of equation (4) indicate that the time lag induced by the first harmonic accounts for most of the pressure sensor measurement lag and that equation (6i) is a good indicator of the overall sensor time lag. Thus, based on the behavior of the first harmonic, the design criteria allow the general dynamical behavior of the pressure sensor to be quickly and easily predicted.

\section{Results and Discussion}

The concepts discussed previously will now be illustrated. First, the frequency response of several sensor geometries and altitudes will be illustrated using the exact solution of equation (4) and the design rules of equations $(6 \mathrm{~g})-(6 \mathrm{i})$. Next, the time response will be illustrated using data synthesized from HI-FADS and other flight data. Power spectra, time history comparisons, and correlation analyses will be presented.

\section{Application of Design Criteria}

Figure 6 presents the calculated frequency response of a typical HI-FADS pressure sensor at 20,000 -ft altitude. Here the frequency response is flat to $10 \mathrm{~Hz}$ and has an attenuation of approximately $1 \mathrm{~dB}$ at $25 \mathrm{~Hz}$. Beyond this frequency, the magnitude rolls-off more steeply. Note that the 2 small resonance harmonics which occur at approximately 90 and $180 \mathrm{~Hz}$ have been 
significantly attenuated by the pneumatic tubing. Because the harmonics are attenuated, their resonances will not distort the measured pressure signal in a significant manner. As calculated using equation (6h), the approximate time delay of the pressure sensing system is $15 \mathrm{msec}$. The HI-FADS system was designed for an operating altitude range between 10,000 and $40,000 \mathrm{ft}$, and the internal pressure sensor geometries were selected by adherence to the design rules of equations $(6 \mathrm{~g})-(6 \mathrm{i})$ as a compromise between these two altitude extremes. At 10,000- $\mathrm{ft}$ altitude the pressure sensors were slightly underdamped, while at 40,000 -ft altitude the sensors were somewhat overdamped.

In figure 6 , both of the harmonics lie beyond the $12.5 \mathrm{~Hz}$ Nyquist frequency of the HI-FADS system. Recall that the sample rate was $25 \mathrm{~Hz}$. If the harmonics were not attenuated, then the resonated noise would have been aliased to the response band of the HI-FADS system. In other words, using significantly wider or shorter lengths of tubing at this altitude would have resulted in degraded pressure measurements. This effect is depicted in Fig. 7, where, instead of using 8-ft tubing lengths, the frequency response resulting from use of $1-\mathrm{ft}$ tubing sections is evaluated. Here a very strong harmonic is present at approximately $215 \mathrm{~Hz}$. In designing a HI-FADS type of airdata system, in which acoustical resonance may be present, great care must be taken to range the pressure sensors to accommodate any magnitude amplification which may be induced by resonance. This is especially true if fine-scale differential measurement transducers are used. If a resonance condition develops and causes noise to be so greatly amplified that the transducer saturates, then this nonlinear process cannot be accounted for and the data will be nonrecoverable.

If significantly thinner or longer lengths of tubing were used, or if the system was operated at a significantly higher altitude, then the response of the measurement sensors would have been greatly attenuated and unacceptable phase delays would have resulted. This effect is illustrated in Fig. 8, where the response of an $L=8 \mathrm{ft}, D=0.06 \mathrm{in}$. sensor is evaluated at 65,000 - $\mathrm{ft}$ altitude. In this case the system is highly overdamped and the approximate sensor time lag, evaluated from equation (6h), is $120 \mathrm{msec}$. Such phase delays are unacceptable for dynamic use.

As a final illustration, if $1-\mathrm{ft}$ tubing lengths are used at 65,000 - $\mathrm{ft}$ altitude, then the system frequency re- sponse again is seen as satisfactory. This case is illustrated in Fig. 9. Here, the frequency response of the pressure measurement sensor is flat to beyond $35 \mathrm{~Hz}$ and no resonant harmonics appear. The approximate time lag is 2 msec.

Because the sensor frequency response characteristics vary so greatly with altitude, it is difficult to select any single sensor geometry which gives acceptable acoustical performance at all altitudes. Fortunately, the problem can be overcome by use of appropriate presample signal conditioning. Using the design rules of equations (6h) and (6i) to identify the location of the primary harmonic, analog filters may be designed to attenuate the resonances. At the same time the frequency response characteristics of the lower frequency band will be preserved. If these filters are coupled to transducers mounted with short sections of pneumatic tubing, then the result is end-to-end pressure sensors which eliminate the resonance effects while leaving the lower frequency band data unaltered. Again, caution must be used in scaling the transducer range to accommodate resonance. If the resonance causes the transducer to saturate, then when the transducer output is run through the low-pass filter the nonlinear distortion caused by the saturation process will result in a gain offset and the measured signal will be biased.

As an example, assume a second-order, low-pass filter with a natural frequency of $50 \mathrm{~Hz}$ and a damping ratio of 0.7071 (Butterworth filter) is coupled with the $L=1 \mathrm{ft}, D=0.06 \mathrm{in}$., $V=0.01 \mathrm{in}^{3}$ sensor geometry at 20,000-ft altitude. For this case the frequency response would appear as in Fig. 10. Comparing this frequency response to Fig. 7, notice that although the resonance peak at $215 \mathrm{~Hz}$ has been significantly attenuated, the frequency response of the system below $40 \mathrm{~Hz}$ is flat. The coupled Butterworth filter adds only $4.5 \mathrm{msec}$ of steady-state time delay to the measured pressure signal. Consequently, in the $40 \mathrm{~Hz}$ and below frequency band, the pressure measurements are essentially free of acoustical distortion.

The frequency response of the same tubing-lowpass filter configuration at 65,000 - $\mathrm{ft}$ altitude is presented in Fig. 11. Here again, up through $40 \mathrm{~Hz}$ the frequency response curve is flat with an attenuation of only $1.5 \mathrm{~dB}$ at $40 \mathrm{~Hz}$. Pressure inputs in this band would be transmitted without significant acoustical distortion. Comparing Fig. 11 to Fig. 9, in the $40 \mathrm{~Hz}$ and below region the magnitude curves show no ap- 
preciable difference and the additional phase lag introduced by the low-pass filter-less than $60^{\circ}$-is negligible. The time delay caused by the low-pass filter at $40 \mathrm{~Hz}$ is $4.2 \mathrm{msec}$.

At this point, a word of caution is appropriate concerning the use of multiplexed or electronically scanned pressure transducers. If multiplexed sensors such as the ESP module are used, then the scan rate must be high enough to clearly capture any significant tubing resonances which occur. Recall that multiplexing is the equivalent of time-sampling, and any harmonic which lies beyond the Nyquist frequency of the scan will appear at a much lower frequency. Consequently, postmultiplexing signal conditioning, either digital or analog, cannot attenuate the aliased resonances. If high scan rates are not possible, or presample signal conditioning is unavailable, the system designer must use the pneumatic transmission line to attenuate the resonances and accept whatever altitude variability occurs. For a HI-FADS type of airdata system, if a wide altitude range is required and presampling filtering cannot be performed, then redundant external ports with internal geometries tailored to specific altitudes can be used.

\section{Flight Data Evaluation}

The spectral distortion effects described in the previous section will now be illustrated using flight-based synthesized data. To accurately simulate the actual presample inputs to the HI-FADS pressure measurement system, a high sample rate ( 500 samples/sec) signal was synthesized from combinations of HI-FADS and other flight data. First, measured HI-FADS pressure data from a pushover-pullup (POPU) maneuver obtained at a Mach number of approximately 0.25 , an angle of attack varying from $10^{\circ}$ to $45^{\circ}$, and an altitude of $20,000 \mathrm{ft}$, were deconvolved using the procedure outlined in Fig. 5, assuming a tubing length of $8 \mathrm{ft}$, a diameter of $0.06 \mathrm{in}$. and a transducer volume of $0.01 \mathrm{in}^{3}$. The deconvolution was performed out to the Nyquist frequency of the system, $12.5 \mathrm{~Hz}$.

The deconvolved HI-FADS pressure data were inherently upper band-limited at $12.5 \mathrm{~Hz}$. The data were merged with 500 samples/sec surface pressure flight data (obtained under similar conditions) by a piezoelectric microphone mounted flush to the aircraft surface. ${ }^{6,8}$ This process was performed to reconstruct the high-frequency end of the pressure spectra. For this analysis, the surface pressure data were lower band-limited using a high-pass filter with a break frequency of $12.5 \mathrm{~Hz}$. The resulting time histories were spliced using a complementary filter in which the transforms of both the deconvolved HI-FADS data and the high-pass-filtered surface pressure data were evaluated. The spectra were scaled and added, and the resulting spectrum was inverse transformed to give a 500 samples/sec time history. The merging process, essentially a complementary filter, was performed for each of the nine HI-FADS pressure measurements. A flowchart of the complementary filtering process is depicted in Fig. 12.

Once the HI-FADS pressure data were deconvolved and merged with the surface measurements, corresponding airdata values were evaluated using the HI-FADS algorithm. For the remainder of this analysis, the deconvolved and merged pressure data will be referred to as the "input" pressure data, and the resulting airdata values will be referred to as the "input" airdata. Input Mach number will be represented by the symbol, $M_{0}$. Input angle of attack will be represented by the symbol, $\alpha_{0}$. The resulting Mach number and angle-of-attack time histories are presented in Fig. 13.

To illustrate the effects of various sensor geometries, the input spectra will now be convolved using the method outlined in Fig. 4. The resulting pressure data will be referred to as the "output" pressure data. The convolved data set will then be passed through the HIFADS algorithm to generate a corresponding airdata set which will be referred to as the "output" airdata. Output Mach number will be represented by the symbol, $M_{L}$. Output angle of attack will be represented by the symbol, $\alpha_{L}$.

First the input pressure data were convolved to simulate the effects of the HI-FADS configuration with $8 \mathrm{ft}$ of 0.06 -in.-diameter pneumatic tubing and a transducer volume of 0.01 in $^{3}$ at $20,000-\mathrm{ft}$ altitude. Comparisons of the input and output spectra are depicted in Fig. 14. Depicted in Fig. 14(a) are the spectral densities obtained from the nosetip pressure port, ESP101. ${ }^{1}$ The ESP101 data are qualitatively representative of all the HI-FADS pressure data. Depicted in Fig. 14(b) are the corresponding angle-of-attack spectral densities. Note that output pressure data, $P_{L}$, show significant power losses at higher frequencies, however, the output angle of attack, $\alpha_{L}$, shows only a minimal power loss when compared to the input angle of attack, $\alpha_{0}$. This effect is a result of the HI-FADS algo- 
rithm least-squares regression eliminating noncoherent, high-frequency noise from the set of nine input HI-FADS pressure measurements. The output pressure data already have been attenuated at higher frequencies by the pressure tubing (convolution) and the resulting input and output angle-of-attack spectra are nearly identical.

Corresponding Mach number and angle-of-attack time histories are presented in Fig. 15. Here, the time scale has been expanded to illustrate time delays and magnitude differences. Note the time lag when comparing the output signals, $M_{L}$ and $\alpha_{L}$, and the input values, $M_{0}$ and $\alpha_{0}$. Cross-correlation analyses between the input and convolved data values indicate that for this geometry the output angle-of-attack signal is acoustically lagged by approximately $15 \mathrm{msec}$. The cross-correlation data are presented in Fig. 16.

The effect of resonance is now illustrated by convolving the input pressure data, assuming a sensor tubing length of $1 \mathrm{ft}$. The diameter is assumed to remain at 0.06 in. and the transducer volume is assumed to remain at $0.01 \mathrm{in}^{3}$. Resulting spectra are presented in Fig. 17. Presented are the spectra for ESP101, and angle of attack. Note that the output pressure is resonated at high frequencies. Also presented are the corresponding angle-of-attack spectra. The regression of the HI-FADS algorithm does not remove the resonated noise, which is coherent, from the input pressure data.

Corresponding Mach number and angle-of-attack time histories are compared in Fig. 18. Again the time scale has been expanded to illustrate the effects. Note that both the output Mach number and angle-of-attack values are noisy. The resonance-induced acoustical noise results in an angle-of-attack noise band of approximately one-half of a degree and the corresponding Mach number noise band is 0.004 .

Since no flight data for extreme altitudes were obtained for phase one of the HARV flight tests, the effects of very high altitudes will now be illustrated by extrapolating flight data to 65,000 - $\mathrm{ft}$ altitude from the maneuver of Fig. 13. The input pressure data were extrapolated to $65,000 \mathrm{ft}\left(\mathrm{kft}=\mathrm{ft} \times 10^{3}\right)$ by assuming that

$$
\frac{(C p \bar{Q})_{65 k f t}}{(C p \bar{Q})_{20 k f t}}=\frac{\left(p_{j}-p_{a}\right)_{65 k f t}}{\left(p_{j}-p_{a}\right)_{20 k f t}}=1
$$

Resulting input Mach number and angle-of-attack time histories, generated by the HI-FADS algorithm, are presented in Fig. 19.

Using the method of Fig. 4, the synthesized input data are convolved assuming a sensor tubing length of $8 \mathrm{ft}$. The diameter and transducer volume remain at $0.06 \mathrm{in}$. and $0.01 \mathrm{in}^{3}$, respectively. The resulting pressure data are passed through the HI-FADS algorithm to give an output airdata set. The resulting angle-of-attack spectra and time histories are compared in Fig. 20. Cross-correlation data are presented in Fig. 21. Note that the output angle-of-attack data are highly lagged, with an approximate time delay of $100 \mathrm{msec}$. This acoustical delay is unacceptable for dynamic usage. The 8-ft tubing section HI-FADS geometry, although giving acceptable performance at $20,000 \mathrm{ft}$, induces unacceptable phase lag at high altitudes.

As discussed earlier, the resonance and lag difficulties can be overcome by use of presample signal conditioning. The performance of the 1-ft tubing length configuration coupled with the $50 \mathrm{~Hz}$ Butterworth filter will now be analyzed. Figure 22 presents the spectral comparions for data obtained from the 20,000$\mathrm{ft}$-altitude maneuver. Notice that most resonanceinduced noise has been removed from the pressure and angle-of-attack signals, and the input and output angle-of-attack spectra are nearly identical. Figure 23 presents the corresponding time history data. Clearly. the resulting time history traces are nearly indistinguishable.

Figure 24 presents similar spectra and time history comparisons for the 65,000 -ft.-altitude maneuver. In this case a $1-\mathrm{ft}$ length of tube is used in conjunction with the $50 \mathrm{~Hz}$ Butterworth filter. The output time delay, unlike the 8-ft tubing data (Fig. 20) is extremely small. Cross-correlation data presented in Fig. 25 indicate that for angle of attack the time delay is on the order of $4 \mathrm{msec}$ as opposed to $100 \mathrm{msec}$ for the 8 - $\mathrm{ft}$ tubing sensor geometry. Thus, using a single pressure sensor geometry, coupled with proper low-pass filter signal conditioning, the HI-FADS system demonstrates quality acoustical performance over a wide altitude range.

\section{Concluding Remarks}

The accuracy of a prototype nonintrusive airdata system designed for high-angle-of-attack measurements was demonstrated for quasi-steady maneuvers 
up to $55^{\circ}$ angle of attack during phase one of the F-18 high alpha research vehicle (HARV) flight test program. The system evaluated in this paper consists of a matrix of nine pressure ports arranged in annular rings on the aircraft nose, and estimates the complete airdata set using flow modeling and nonlinear regression. The system performed well for steady or moderate maneuvering flight conditions and computations were performed at a rate of 25 samples/sec. Satisfactory frequency response was verified up to the system Nyquist frequency of $12.5 \mathrm{~Hz}$. For higher frequencies there is some question as to how well the high-angle-of-attack flush airdata sensing (HI-FADS) system would perform. This paper addresses one of the primary reasons for this concem: the effects of acoustical distortions within the individual pressure sensors of the HI-FADS pressure matrix.

To quantify these effects, a dynamic model which describes acoustical distortion was developed and solved in closed form for frequency response. The model was briefly verified by comparison to lab data. Simple design criteria which describe the dynamics of the primary harmonic were developed from the model. Use of these criteria allows for the geometry of the pressure measurement system to be tailored to a particular frequency band or operating altitude.

Using an input pressure data set, synthesized from HI-FADS and surface pressure measurements, the effects of various internal sensor geometries and presample filtering were analyzed and qualitatively evaluated. Analyses and data presented indicate that the sensor frequency response characteristics vary greatly with altitude, thus it is difficult to select any single sensor geometry which gives acceptable acoustical performance at all altitudes.

The altitude variability problem is overcome by using presample signal conditioning to eliminate the resonance effects. Caution must be used in scaling the transducer range to accommodate resonance. If the resonance causes the transducer to saturate, then when the transducer output is run through the low-pass filter, the nonlinear distortion caused by the saturation process will result in a gain offset. Consequently the measured signal will be biased. Furthermore, caution should be exercised if multiplexed or electronically scanned pressure transducers are to be used in the nonintrusive airdata system. If multiplexed sensors such as the electronically scanned pressure (ESP) module are to be used, then the scan rate must be high enough to clearly capture any significant tubing resonances. Any harmonic which lies beyond the Nyquist frequency of the scan will be aliased and appear at a lower frequency within the band of interest.

\section{References}

${ }^{1}$ Whitmore, Stephen A., Moes, Timothy R., and Larson, Terry J., Preliminary Results From a Subsonic High Angle-of-Attack Flush Airdata Sensing (HI-FADS) System: Design, Calibration, and Flight Test Evaluation, NASA TM-101713, 1990.

${ }^{2}$ Larson, Terry J., Whitmore, Stephen A., Ehemberger, L.J., Johnson, J. Blair, and Siemers, Paul M., III, Qualitative Evaluation of a Flush Air Data System at Transonic Speeds and High Angles of Attack, NASA TP-2716, 1987.

${ }^{3}$ Larson, Terry J., and Siemers, Paul M., III, Use of Nose Cap and Fuselage Pressure Orifices for Determination of Air Data for Space Shuttle Orbiter Below Supersonic Speeds, NASA TP-1643, 1980.

${ }^{4}$ Moes, Timothy R., and Whitmore, Stephen A., "Preliminary Results from an Airdata Enhancement Algorithm with Application to High-Angle-of-Attack Flight," AIAA 91-0672, Jan. 1991.

${ }^{5}$ Whitmore, Stephen A., Formulation of a General Technique for Predicting Pneumatic Attenuation Errors in Airborne Pressure Sensing Devices, NASA TM-100430, 1988.

${ }^{6}$ Whitmore, Stephen A., Lindsey, William T., Curry, Robert E., and Gilyard, Glenn B., Experimental Characterization of the Effects of Pneumatic Tubing on Unsteady Pressure Measurements, NASA TM-4171, 1990.

${ }^{7}$ Whitmore, Stephen A., Formulation and Verification of a Technique for Compensation of Pneumatic Attenuation Errors in Airborne Pressure Sensing Devices, Ph.D Dissertation, University of Califomia, Los Angeles, University Microfilms Intemational, 1989.

${ }^{8}$ Whitmore, Stephen A., and Leondes, Comelius, T., Compensation for Pneumatic Distortion in Pressure Sensing Devices, NASA TM-101716, 1990.

9 Stephens, R.W.B., and Bate, A.E., Acoustics and Vibrational Physics, St. Martin's Press, Inc., NY, 1966. 
${ }^{10}$ Schlichting, Hermann (J. Kestin, transl.), Boundary Layer Theory, McGraw-Hill Book Co. Inc., NY, 1960.

${ }^{11}$ Schuder, C.B., and Binder, R.C., "The Response of Pneumatic Transmission Lines to Step Inputs," Transactions of the American Society of Mechanical Engineers (ASME), vol. 81, no. 4, Dec. 1959, pp. 578584.

${ }^{12}$ Hougen, J.O., Martin, O.R., and Walsh, R.A., "Dynamics of Pneumatic Transmission Lines," Control Engineering, vol. 10, Sept. 1963, pp. 114-117.

${ }^{13}$ Mendel, Jerry M., Optimal Seismic Deconvolution, An Estimation-Based Approach, Academic Press, NY, 1983.

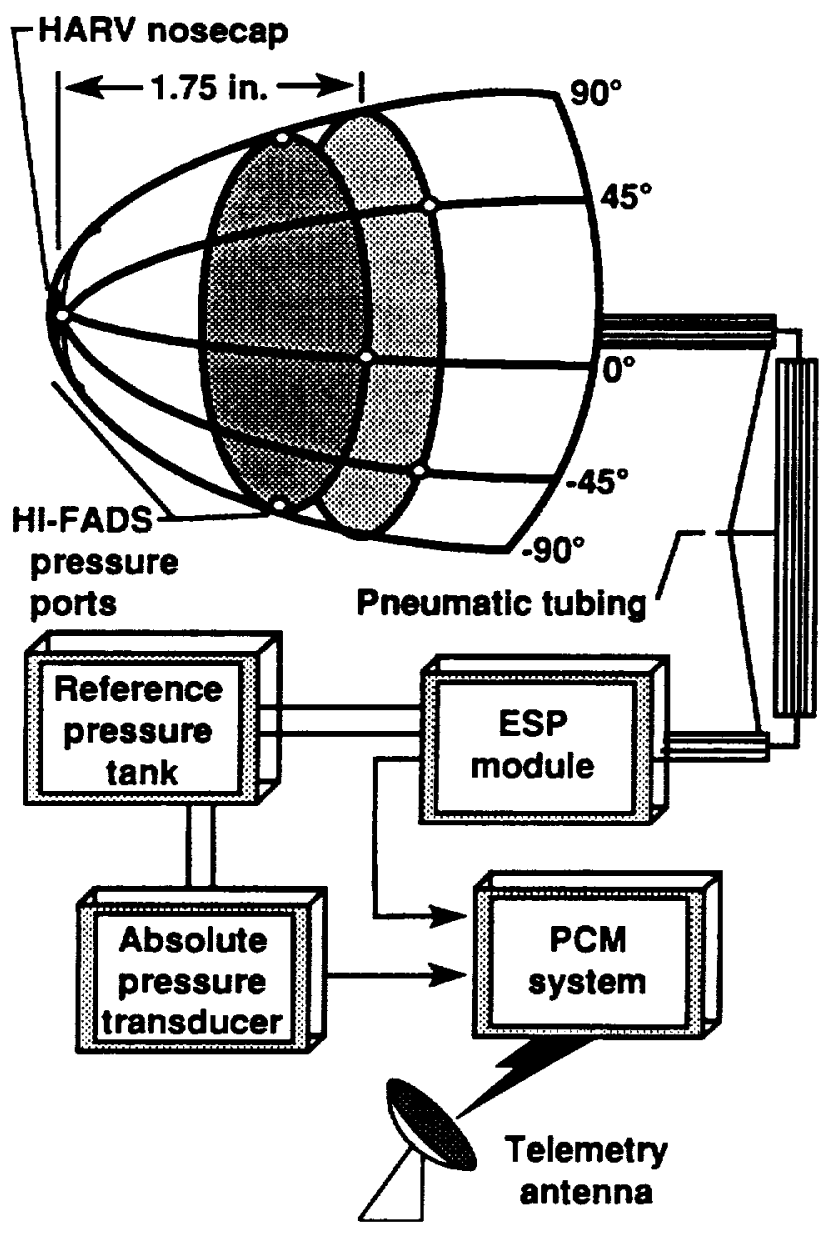

200508

Fig. 1 Schematic of HI-FADS system.
${ }^{14}$ Bendat, Julius S., and Piersol, Allan G., Random Data: Analysis and Measurement Procedures, WileyInterscience, NY, 1971.

${ }^{15}$ Franklin, Gene F., and Powell, J. David, Digital Control of Dynamic Systems, Addison-Wesley Publishing Co., Reading MA, 1980.

${ }^{16}$ The International Dictionary of Applied Mathematics, D. Van Nostrand Co., Inc., Princeton, NJ, 1960.

${ }^{17}$ Lamb, 1st Lt. J.P., Jr., The Influence of Geometry Parameters Upon Lag Error in Airborne Pressure Measuring Systems, WADC TR 57-351, July 1957.

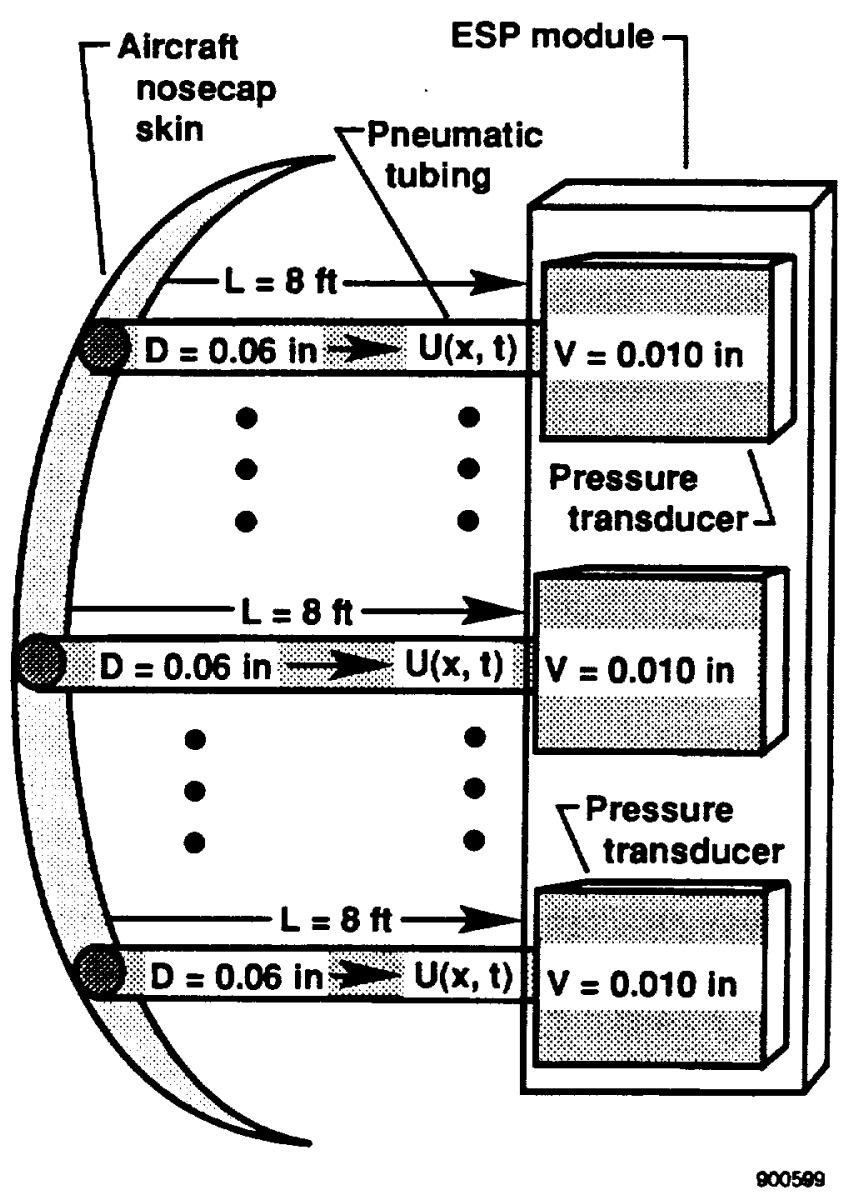

Fig. 2 Schematic of HI-FADS pressure sensing system internal geometry. 


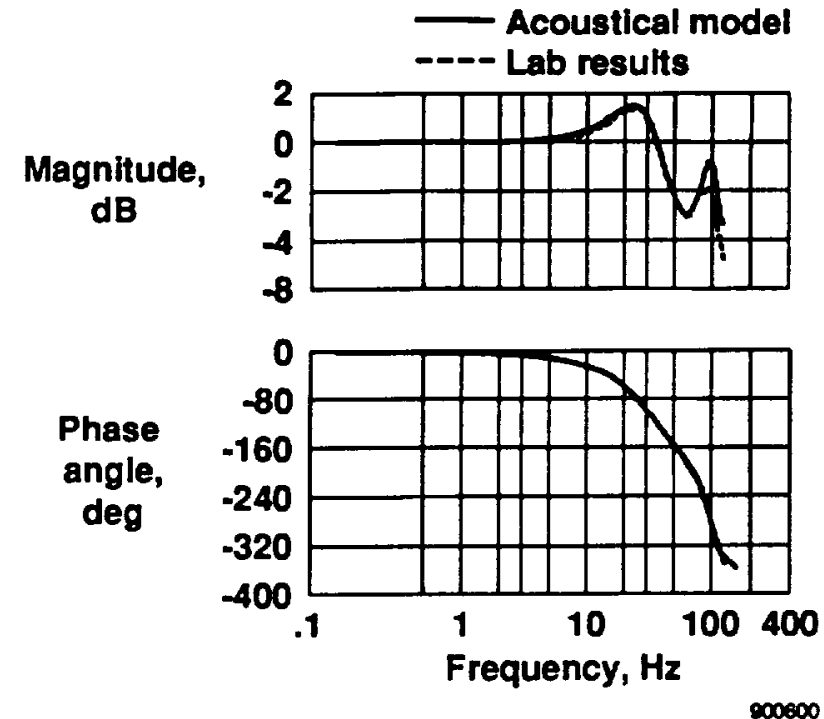

Fig. 3 Comparison of accoustical model frequency response to laboratory data for HI-FADS sensor geometry, 2300-ft altitude.
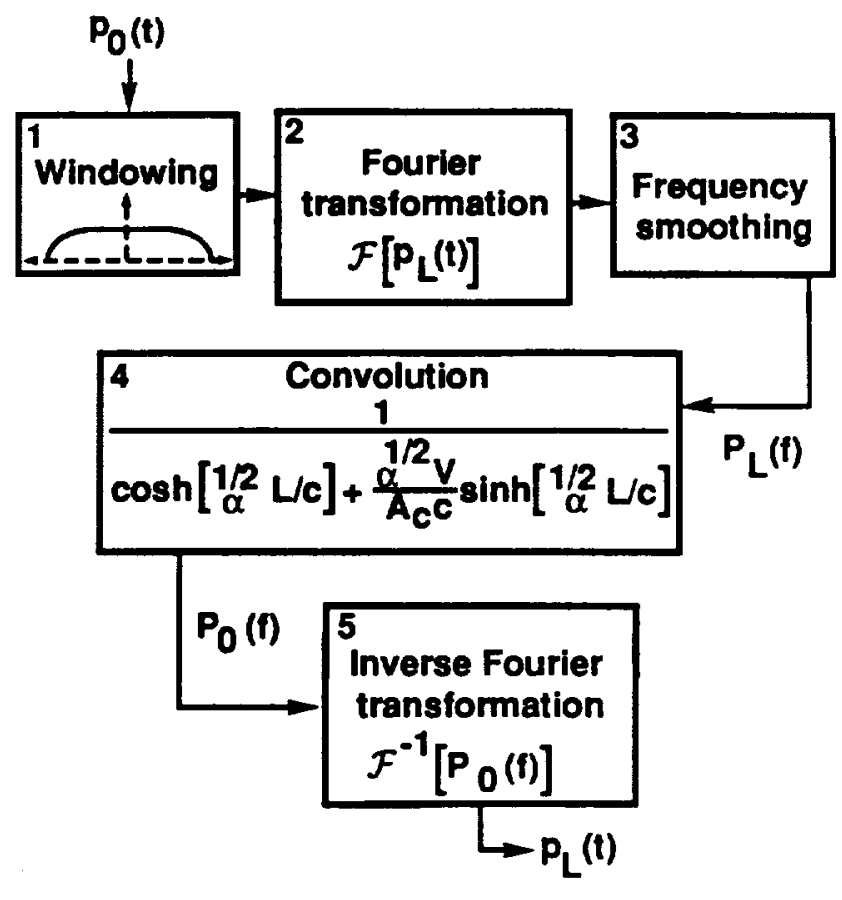

Fig. 4 Schematic of spectral convolution scheme.

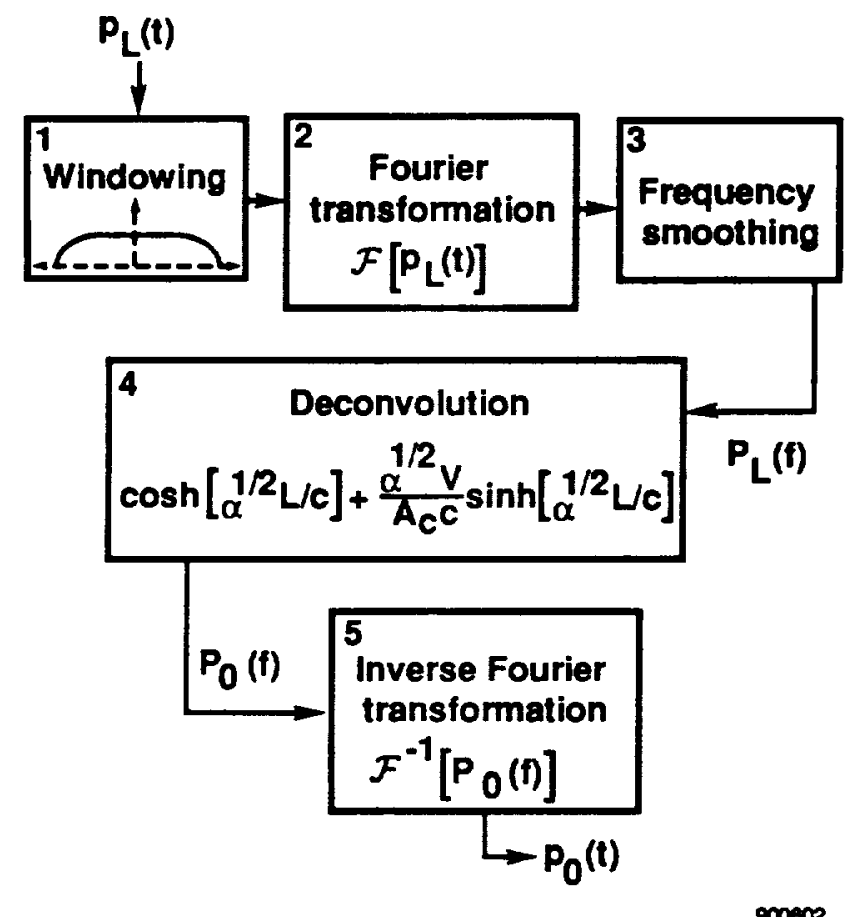

Fig. 5 Schematic of spectral deconvolution scheme. 


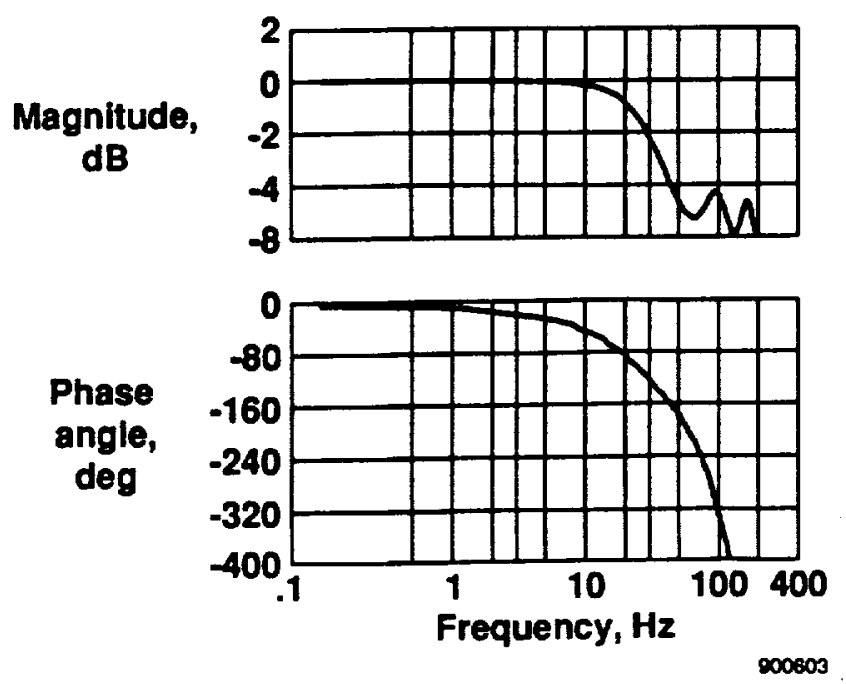

Fig. 6 Calculated frequency response of typical HI-FADS pressure sensor, $L=8 \mathrm{ft}, D=0.06$ in., $H_{p}=$ $20,000 \mathrm{ft}$.
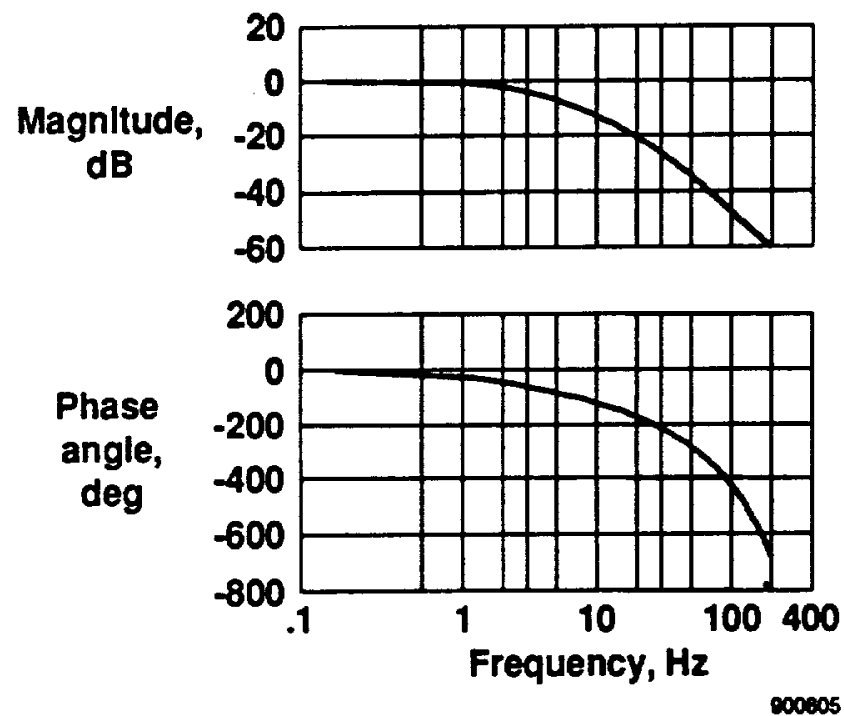

Fig. 8 Calculated sensor frequency response; $L=8 \mathrm{ft}$, $D=0.06$ in., $V=0.01 \mathrm{in}^{3}, H_{p}=65,000 \mathrm{ft}$.

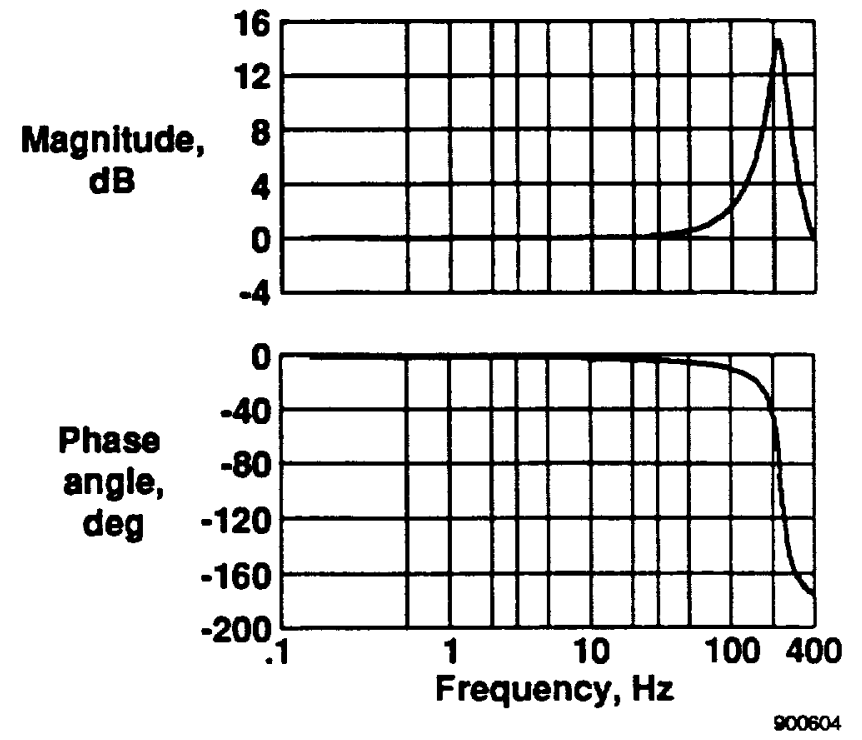

Fig. 7 Calculated sensor frequency response; $L=1 \mathrm{ft}$, $D=0.06$ in., $V=0.01 \mathrm{in}^{3}, H_{p}=20,000 \mathrm{ft}$.



Fig. 9 Calculated sensor frequency response; $L=1 \mathrm{ft}$, $D=0.06$ in., $V=0.01 \mathrm{in}^{3}, H_{p}=65,000 \mathrm{ft}$. 


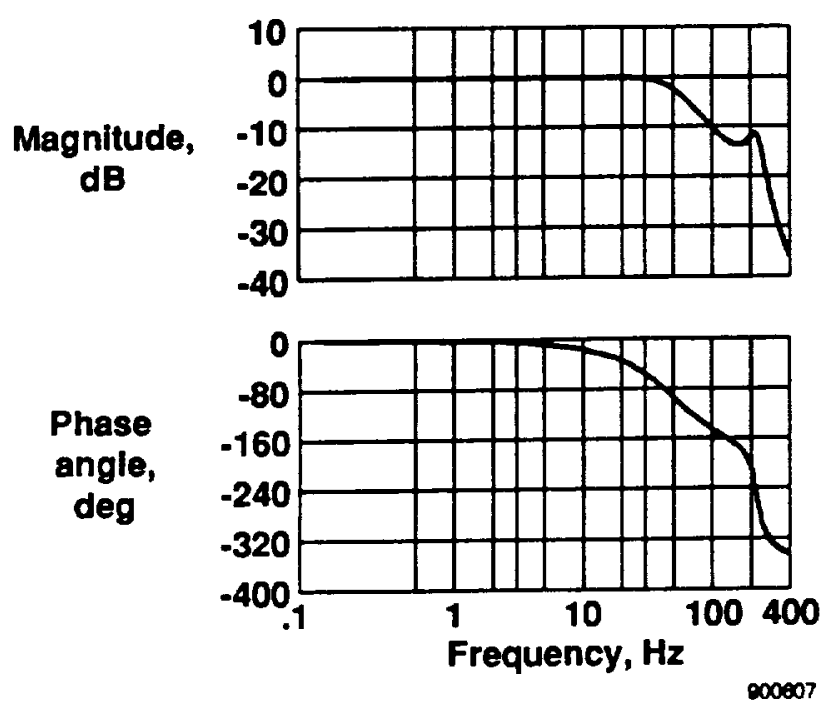

Fig. 10 Calculated sensor frequency response; $L=$ $1 \mathrm{ft}, D=0.06$ in., $V=0.01 \mathrm{in}^{3}, H_{p}=20,000 \mathrm{ft}$; coupled with second-order, $50 \mathrm{~Hz}$ Butterworth filter.

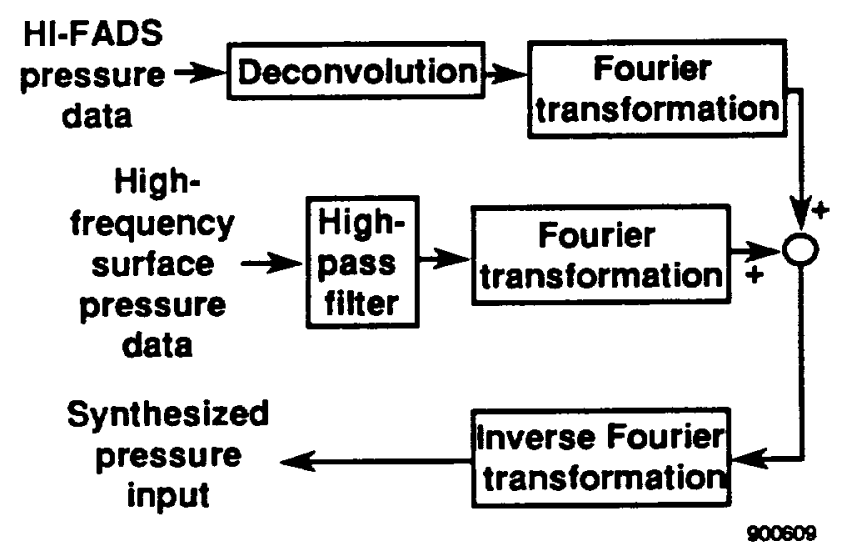

Fig. 12 Complementary filtering scheme for merging pressure data.
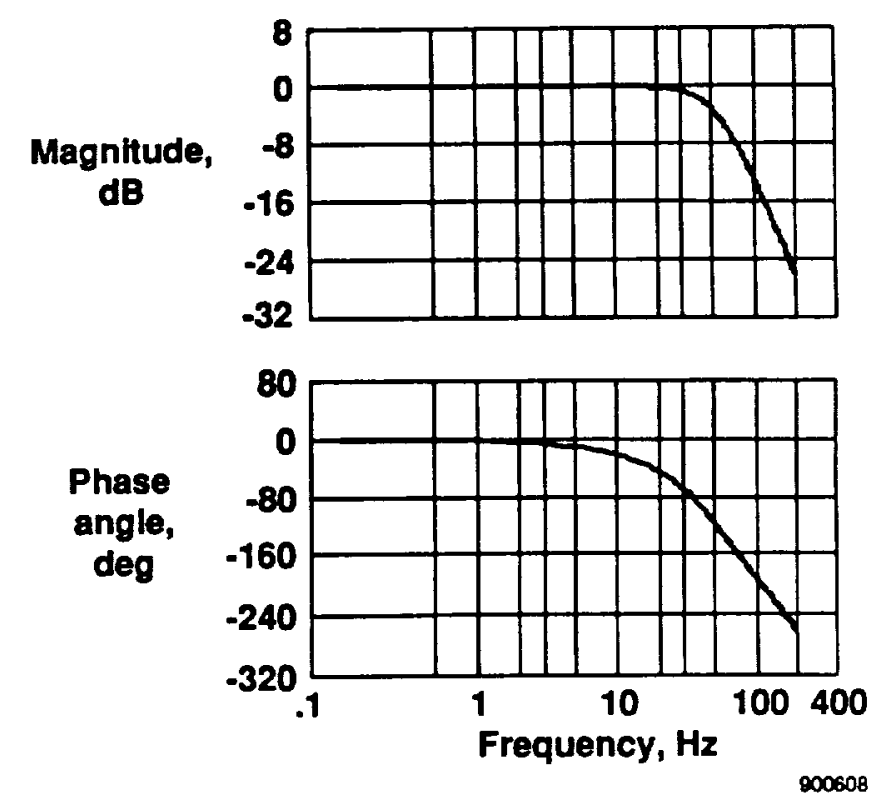

Fig. 11 Calculated sensor frequency response; $L=$ $1 \mathrm{ft}, D=0.06$ in., $V=0.01 \mathrm{in}^{3}, H_{p}=65,000 \mathrm{ft}$; coupled with second-order, $50 \mathrm{~Hz}$ Butterworth filter.

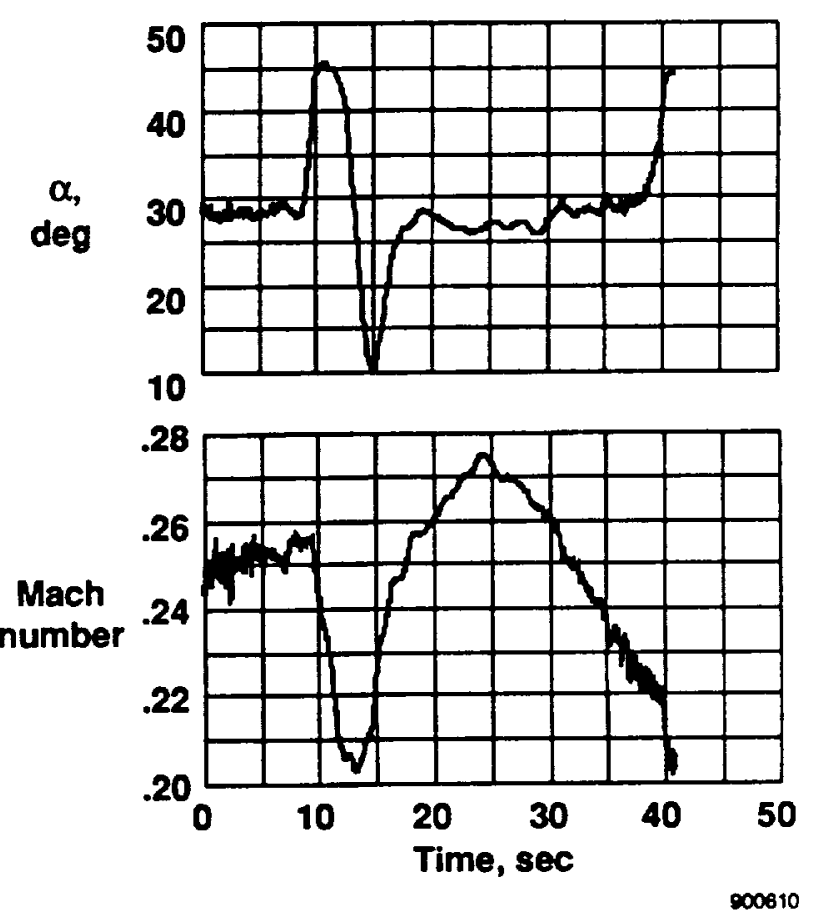

Fig. 13 Time history of 20,000-ft altitude pushoverpullup maneuver. 


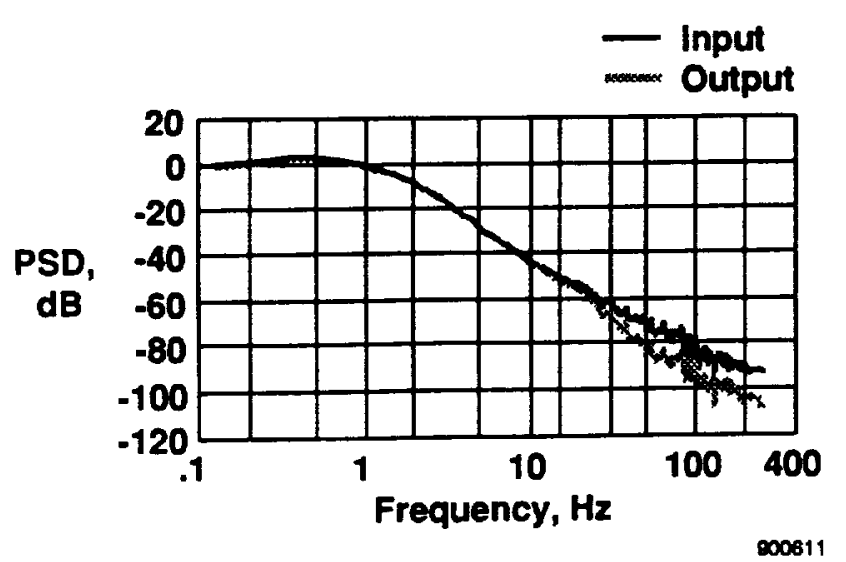

(a) ESP101.

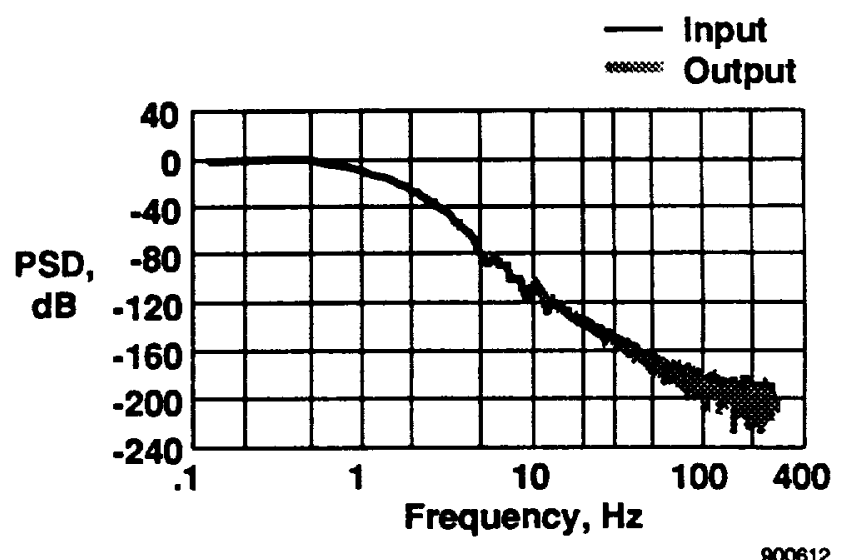

(b) Angle of attack.

Fig. 14 Comparisons of input and output power spectra: ESP101 pressure and HI-FADS angle of attack.

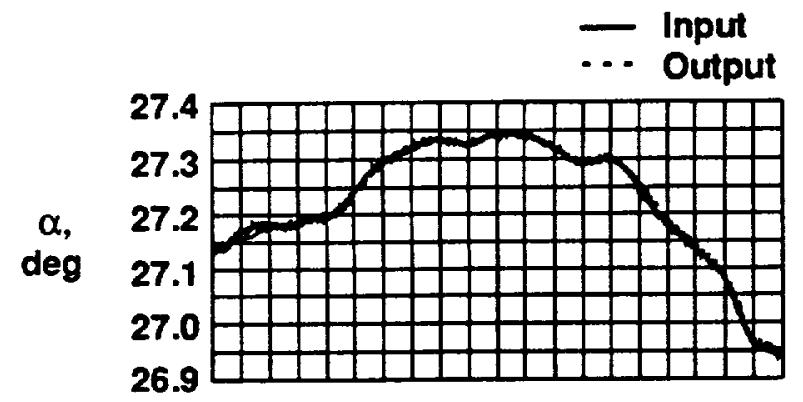

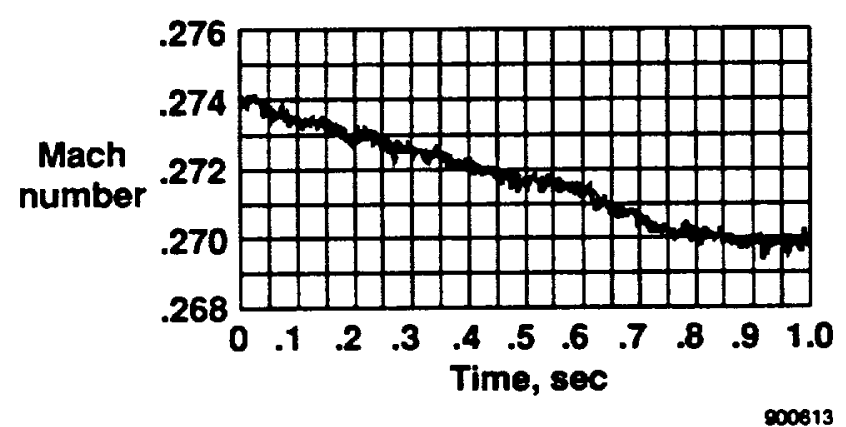

Fig. 15 Time history comparisons of input and output HI-FADS parameter values, angle of attack, and Mach number.

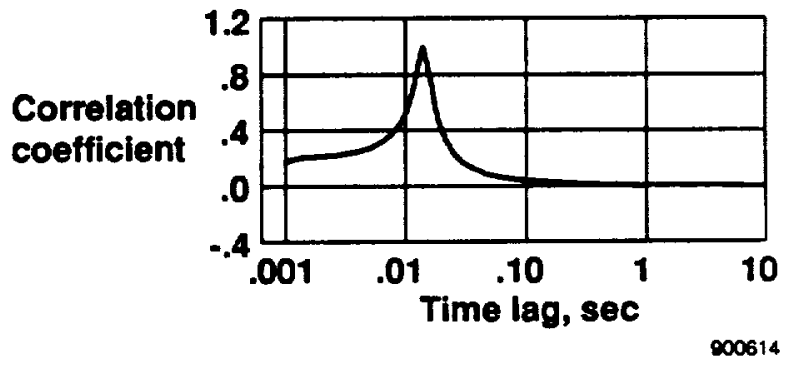

Fig. 16 HI-FADS angle-of-attack time delay; correlation of input and output values. 


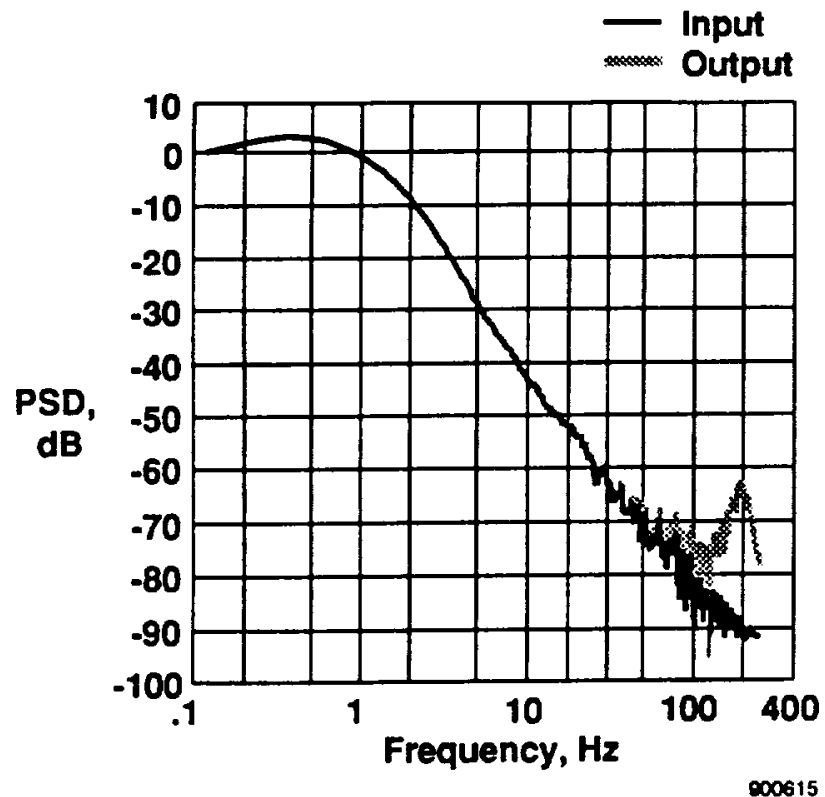

(a) ESP101.

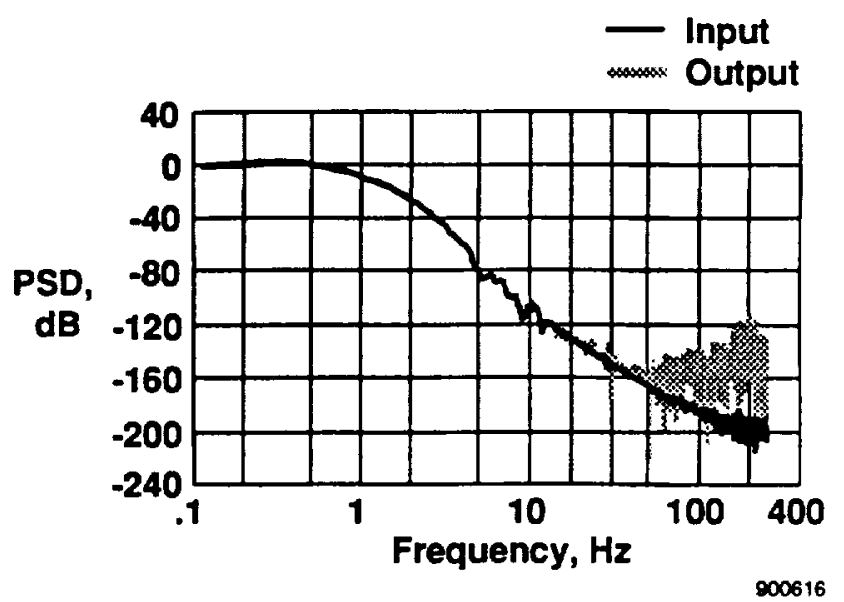

(b) Angle of attack.

Fig. 17 Comparisons of input and output power spectra: ESP101 pressure and HI-Fi. SS angle of attack; $L=1 \mathrm{ft}$, $H_{p}=20,000 \mathrm{ft}$.
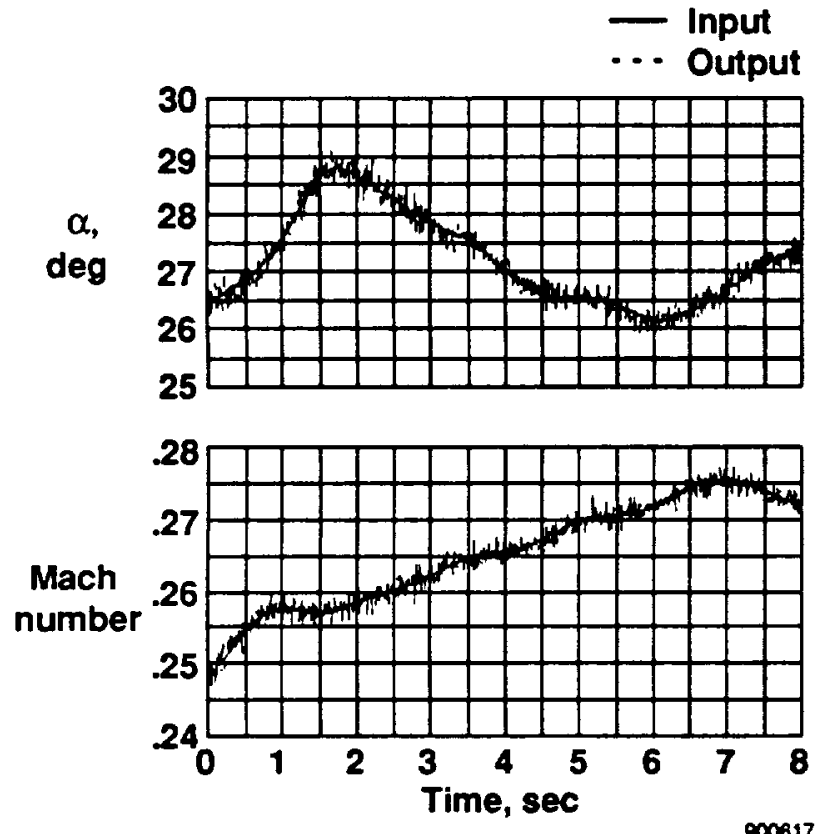

Fig. 18 Time history comparisons on input and output HI-FADS parameter values: angle of attack, and Mach number, $L=1 \mathrm{ft} ; H_{\mathrm{p}}=20,000 \mathrm{ft}$.
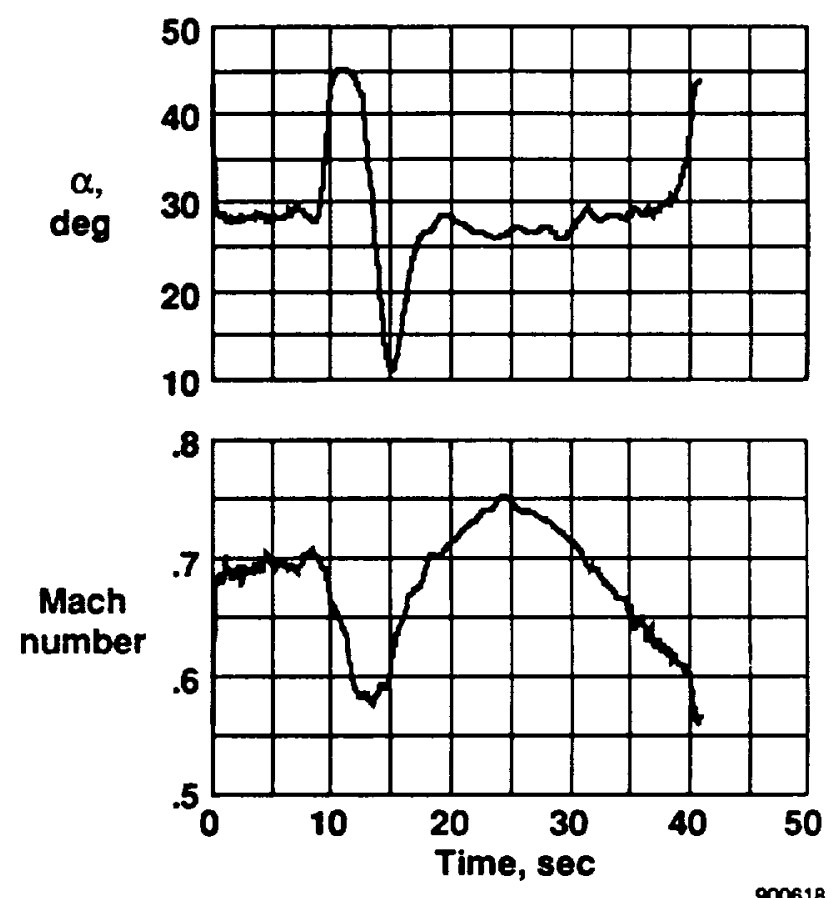

Fig. 19 Time history of $65,000-\mathrm{ft}$ altitude simulated pushover-pullup maneuver. 


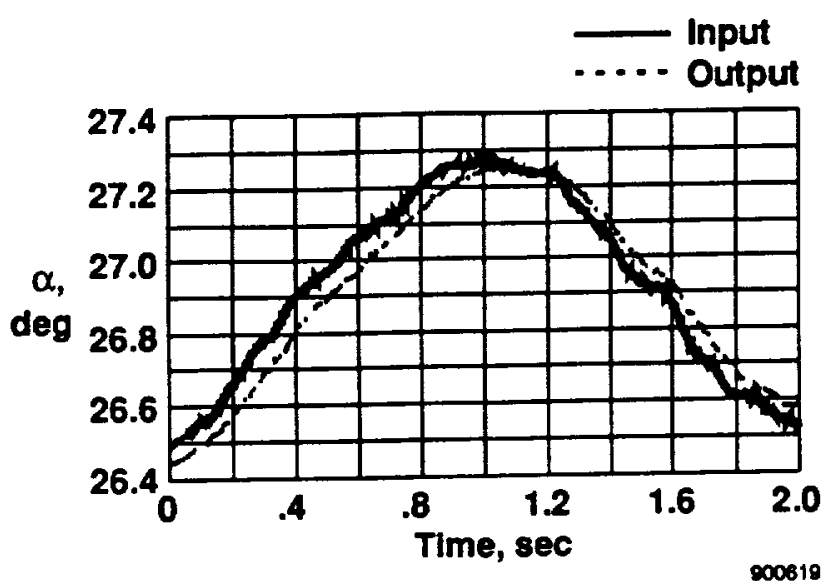

(a) Time history.

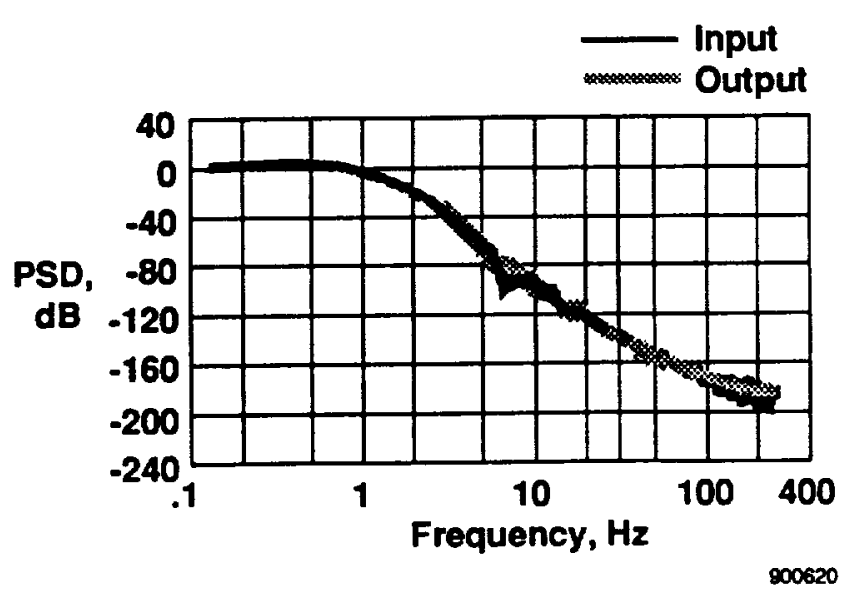

(b) PSD.

Fig. 20 Comparisons of input and output time history and power spectra: HI-FADS angle of attack; $L=8 \mathrm{ft}, H_{p}=$ $65,000 \mathrm{ft}$.



Fig. 21 HI-FADS angle-of-attack time delay: correlation of input and output values; $L=8 \mathrm{ft}, H_{\mathrm{p}}=65,000 \mathrm{ft}$. 


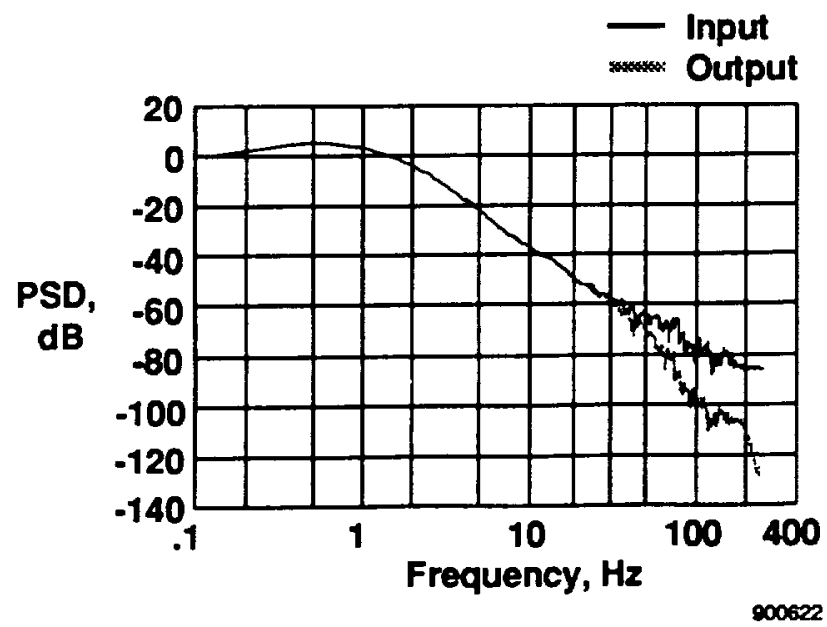

(a) ESP101.

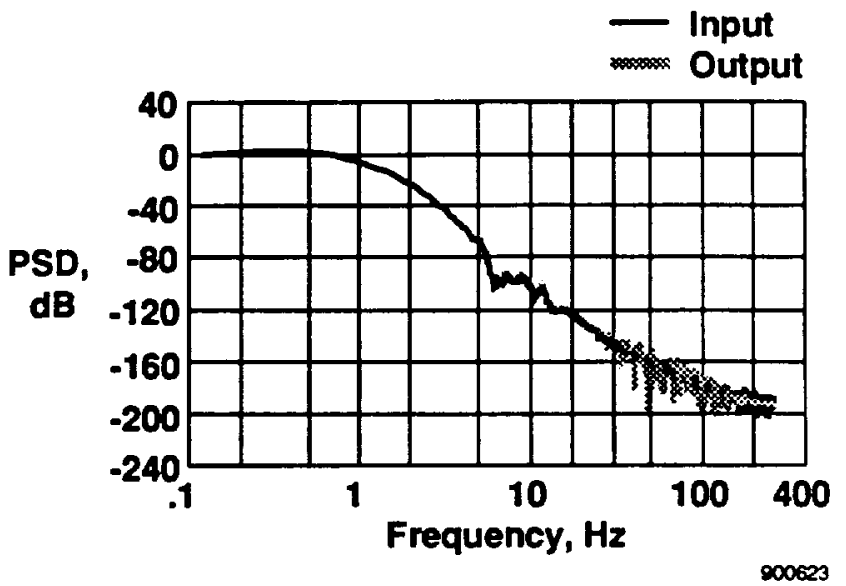

(b) Angle of attack.

Fig. 22 Comparisons of input and output power spectra: ESP101 pressure and HI-FADS angle of attack; $L=1 \mathrm{ft}$, $H_{p}=20,000 \mathrm{ft}$, with $50 \mathrm{~Hz}$ antialiasing filter.

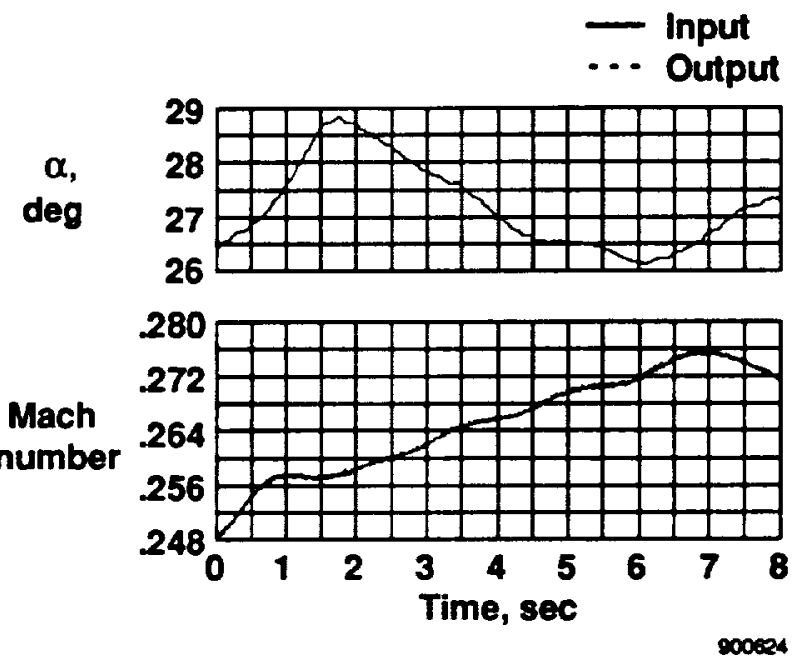

Fig. 23 Time history comparisons of input and output (resonated) HI-FADS parameter values, angle of attack, and Mach number, $L=1 \mathrm{ft}, H_{p}=20,000 \mathrm{ft}$, with $50 \mathrm{~Hz}$ antialiasing filter. 


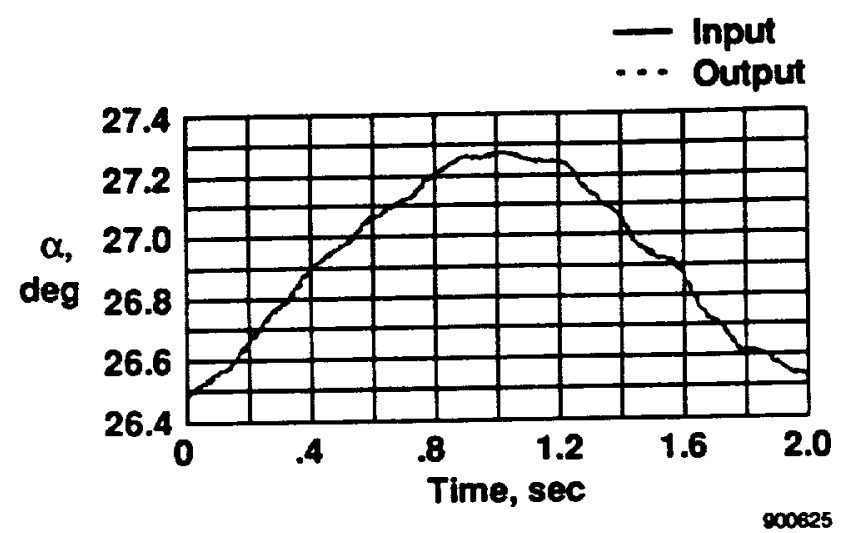

(a) Time history.

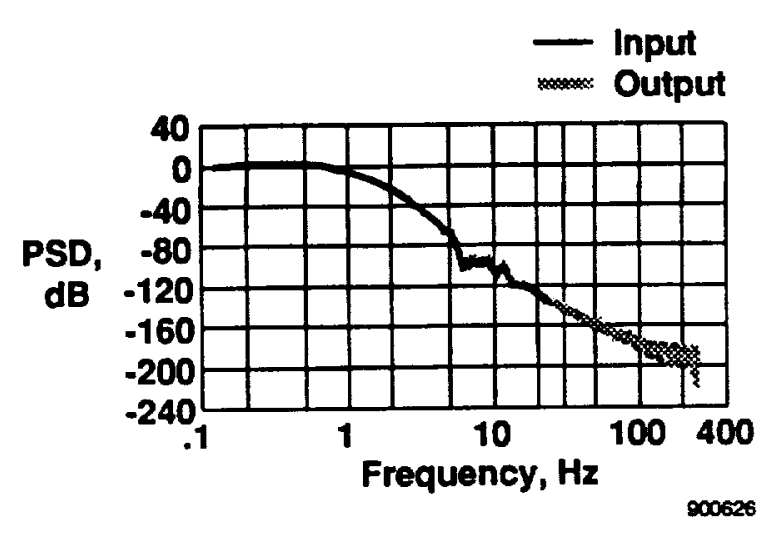

(b) PSD.

Fig. 24 Comparisons of input and output time history and power spectra: HI-FADS angle of attack; $L=1 \mathrm{ft}, H_{p}=$ $65,000 \mathrm{ft}$, with $50 \mathrm{~Hz}$ antialiasing filter.

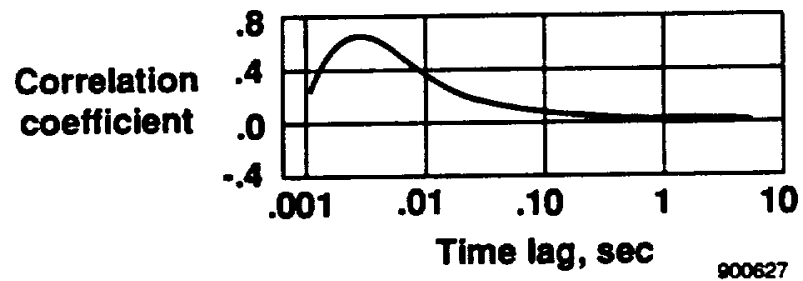

Fig. 25 HI-FADS angle-of-attack sensor time delays: correlation of input and output values; $L=1 \mathrm{ft}, H_{p} 65,000 \mathrm{ft}$, with $50 \mathrm{~Hz}$ low-pass filter. 


\begin{tabular}{|c|c|c|c|c|}
\hline NSS & \multicolumn{4}{|c|}{ Report Documentation Page } \\
\hline $\begin{array}{l}\text { 1. Report No. } \\
\text { NASA TM-101736 }\end{array}$ & \multicolumn{2}{|c|}{ 2. Govermment Accossion No. } & \multicolumn{2}{|c|}{ 3. Recipient's Catalog No. } \\
\hline \multirow{2}{*}{\multicolumn{3}{|c|}{$\begin{array}{l}\text { 4. Title and Subcitle } \\
\text { The Effects of Pressure Sensor Acoustics on Airdata Derived From } \\
\text { a High-Angle-of-Attack Flush Airdata Sensing (HI-FADS) System }\end{array}$}} & \multicolumn{2}{|c|}{$\begin{array}{l}\text { 5. Report Date } \\
\text { February } 1991\end{array}$} \\
\hline & & & \multicolumn{2}{|c|}{ 6. Pertorming Organization Code } \\
\hline \multirow{2}{*}{\multicolumn{3}{|c|}{$\begin{array}{l}\text { 7. Author(s) } \\
\text { Stephen A. Whitmore and Timothy R. Moes }\end{array}$}} & \multicolumn{2}{|c|}{$\begin{array}{l}\text { 8. Pertorming Organization Report No. } \\
\text { H-1690 }\end{array}$} \\
\hline & & & \multicolumn{2}{|c|}{$\begin{array}{l}\text { 10. Work Unit No. } \\
\text { RTOP 505-60-21 }\end{array}$} \\
\hline \multirow{2}{*}{\multicolumn{3}{|c|}{$\begin{array}{l}\text { 9. Pertorming Organization Name and Address } \\
\text { NASA Ames Research Center } \\
\text { Dryden Flight Research Facility } \\
\text { P.O. Box 273, Edwards, CA 93523-0273 }\end{array}$}} & \multicolumn{2}{|c|}{ 11. Contract or Grant No. } \\
\hline & & & \multirow{2}{*}{\multicolumn{2}{|c|}{$\begin{array}{l}\text { 13. Type of Report and Period Covered } \\
\text { Technical Memorandum }\end{array}$}} \\
\hline \multirow{2}{*}{\multicolumn{3}{|c|}{$\begin{array}{l}\text { 12. Sponsoring Agency Name and Address } \\
\text { National Aeronautics and Space Administration } \\
\text { Washington, DC 20546-3191 }\end{array}$}} & & \\
\hline & & & \multicolumn{2}{|c|}{ 14. Sponsoring Agency Code } \\
\hline \multicolumn{5}{|c|}{$\begin{array}{l}\text { Prepared as AIAA 91-0671 for presentation at the AIAA 29th Aerospace Sciences Meeting, } \\
\text { Reno, Nevada, January 7-10,1991. }\end{array}$} \\
\hline \multicolumn{5}{|c|}{$\begin{array}{l}\text { 16. Abstract } \\
\text { The accuracy of a nonintrusive high-angle-of-attack flush airdata sensing (HI-FADS) system was } \\
\text { verified for quasi-steady flight conditions up to } 55^{\circ} \text { angle of attack during the F-18 High Alpha Research } \\
\text { Vehicle (HARV) Program. The system is a matrix of nine pressure ports arranged in annular rings on the } \\
\text { aircraft nose. The complete airdata set is estimated using nonlinear regression. Satisfactory frequency } \\
\text { response was verified to the system Nyquist frequency (12.5 Hz). The effects of acoustical distortions } \\
\text { within the individual pressure sensors of the nonintrusive pressure matrix on overall system performance } \\
\text { are addressed. To quantify these effects, a frequency-response model describing the dynamics of } \\
\text { acoustical distortion is developed and simple design criteria are derived. The model adjusts measured } \\
\text { HI-FADS pressure data for the acoustical distortion and quantifies the effects of internal sensor geometries } \\
\text { on system performance. Analysis results indicate that sensor frequency response characteristics vary } \\
\text { greatly with altitude, thus it's difficult to select satisfactory sensor geometry for all altitudes. The solution } \\
\text { uses presample filtering to eliminate resonance effects, and short pneumatic tubing sections to reduce lag } \\
\text { effects. Without presample signal conditioning the system designer must use the pneumatic transmission } \\
\text { line to attenuate the resonances and accept the resulting altitude variability. }\end{array}$} \\
\hline \multicolumn{2}{|c|}{$\begin{array}{l}\text { 17. Key Words (Suggested by Author(s)) } \\
\text { Acoustics of pressure sensors; Airdata; } \\
\text { Boundary value problems; Deconvolution; } \\
\text { Flush port }\end{array}$} & $\begin{array}{l}\text { 18. Distribution Str } \\
\text { Unclassifie }\end{array}$ & Unlimited & +2 \\
\hline $\begin{array}{l}\text { 19. Security Classif. (of this report) } \\
\text { Unclassified }\end{array}$ & $\begin{array}{l}\text { 20. Security C } \\
\text { Unclass }\end{array}$ & is page) & $\begin{array}{c}\text { 21. No. of Pages } \\
23\end{array}$ & $\begin{array}{r}\text { 22. Price } \\
\text { A02 }\end{array}$ \\
\hline
\end{tabular}

NASA FORM 1626 oct 20 For sale by the National Technical Information Service, Springfield, Virginia 22161-2171 
